Economia e Sociedade, Campinas, Unicamp. IE. http://dx.doi.org/10.1590/1982-3533.2018v27n3art1 1

\title{
Influência do Programa Bolsa Família na alocação de recursos: uma análise considerando a presença de mulheres no domicílio *
}

\author{
Mirian Aparecida Rocha ** \\ Leonardo Bornacki de Mattos * \\ Alexandre Bragança Coelho ${ }^{* * * *}$
}

\section{Resumo}

O Programa Bolsa Família (PBF) é o principal programa de transferência de renda do Brasil e representa um incremento de renda nos domicílios, que alocam esses recursos entre diversas categorias de consumo. O objetivo deste trabalho foi identificar em que medida o PBF alterou o valor do dispêndio em cada categoria e as parcelas de dispêndio. Foram utilizadas as Pesquisas de Orçamentos Familiares (POFs) de 2002-2003 e de 2008-2009 e os métodos Propensity Score Matching (PSM), Diferenças em Diferenças e Seemingly Unrelated Regressions (SUR). Os resultados indicaram maior impacto do PBF sobre alimentação e habitação, tanto em termos absolutos como em relativos. Contudo, o efeito sobre alimentação foi surpreendentemente negativo, enquanto o impacto sobre habitação foi positivo. Foi possível concluir que destinar renda preferencialmente às mulheres não afeta o consumo de fumo. Além disso, nos domicílios em que as mulheres têm total autonomia para alocar a renda do PBF, o impacto do acréscimo da renda foi maior.

Palavras-chave: Consumo intradomiciliar; Programas de transferência de renda; Políticas públicas; Alocação da renda; Parcelas de dispêndio.

\begin{abstract}
Impact of the Bolsa Familia program on the allocation of resources in Brazilian households: an analysis considering women in the households

Brazil's Conditional Cash Transfer program, Bolsa Família Program - PBF (Family Allowance), represents a major increase in household income in the country. Households allocate these resources among several consumption categories. This work aimed to identify the impact of the PBF on the expenditure value of each category and on the share of expenditure. Data from the household budget survey - $P O F$, carried out in 2002-2003 and 2008-2009, were used. The following methodologies were combined: Propensity Score Matching (PSM), Differences-in-Differences (DD), and Seemingly Unrelated Regressions (SUR). The results indicate that the largest impact of the PBF was on food and housing, both in absolute and relative terms. However, the effect on food was surprisingly negative. On the other hand, the impact on housing was positive. It was possible to conclude that directing income to women
\end{abstract}

* Artigo recebido em 12 de novembro de 2015 e aprovado em 2 de março de 2018. Agradecimentos ao apoio financeiro recebido da Fapemig por meio do edital Demanda Universal 2015 (Processo APQ-02933-15) e a colaboração da Professora Helena Perrone da Universitat Pompeu Fabra de Barcelona.

** Doutora em Economia Aplicada pela Universidade Federal de Viçosa (UFV), Viçosa, MG, Brasil. E-mail: mirianapr2004@yahoo.com.br.

${ }^{* * *}$ Professor do Departamento de Economia Rural da Universidade Federal de Viçosa, Viçosa, MG, Brasil. Bolsista de Produtividade em Pesquisa do CNpq. E-mail: lbmattos@ufv.br.

${ }^{* * * *}$ Professor do Departamento de Economia Rural da Universidade Federal de Viçosa, Viçosa, MG, Brasil. Bolsista de Produtividade em Pesquisa do CNPq. E-mail: acoelho@ufv.br. 
Mirian Aparecida Rocha, Leonardo Bornacki de Mattos, Alexandre Bragança Coelho

does not affect the consumption of tobacco. The impact of the PBF is also larger in households where women have the autonomy to decide how to allocate the PBF.

Keywords: Intrahousehold consumption; Conditional cash transfer; Public policy; Income allocation; Share of expenditure.

JEL D12, I38, R22.

\section{Introdução}

No Brasil, os programas sociais de transferência de renda são bastante recentes, tendo sua origem na década de 1990, passando a receber maior atenção, a partir de 2003, com a criação do Programa Bolsa Família - PBF, que resultou da unificação dos Programas Bolsa Escola, Bolsa Alimentação, Programa Nacional de Acesso à Alimentação, Auxílio Gás e Cadastro Único ${ }^{1}$. Desde sua implementação, o PBF vem recebendo um montante de recursos crescente, de modo que, para 2014, a Lei Orçamentária Anual (LOA) previa um gasto de cerca de $\mathrm{R} \$ 25$ bilhões com o programa e o número de beneficiados já alcançou 14 milhões de famílias, o equivalente a cerca de 50 milhões de pessoas (MDS, 2014).

O Programa Bolsa Família é um programa de transferência de renda condicionada do governo brasileiro, que tem como objetivo beneficiar famílias em situação de pobreza e extrema pobreza. Para fins do programa, são consideradas extremamente pobres as famílias com renda familiar per capita de até $\mathrm{R} \$ 77,00$ e pobres, aquelas com renda familiar per capita entre $\mathrm{R} \$ 77,00$ e $\mathrm{R} \$ 154,00$. Estas, para receberem o benefício, devem possuir crianças ou adolescentes de 0 a 17 anos de idade na sua composição. O benefício é pago, preferencialmente, à mulher e depende do tamanho da família, da idade dos membros e da renda familiar.

Segundo Thomas e Chen (1994), as políticas públicas podem interferir na forma como as decisões são tomadas dentro do domicílio, e as implicações disso devem ser consideradas. Com isso, acredita-se que o PBF, ao destinar o benefício preferencialmente às mulheres, faz com que o poder das mulheres seja aumentado na hora de alocar a renda familiar, podendo alterar a proporção de gastos com as categorias de consumo. Homens e mulheres podem apresentar preferências distintas em relação aos bens, o que pode ficar evidente quando o poder dos membros do domicílio se altera como resultado da mudança da proporção da renda auferida por cada um.

Assim, o aumento de renda proporcionado pelo Programa Bolsa Família provavelmente gera modificações nas parcelas de dispêndio com bens de consumo das famílias beneficiárias, e essa variação é influenciada pela composição familiar. Segundo Angelucci e Attanasio (2013), os programas de transferência de renda podem mudar a demanda familiar de duas formas:

(1) O PBF foi criado por meio da Medida Provisória n. 132, de 2003, que se converteu na Lei n. 10.836, em 9 de janeiro de 2004 
Influência do Programa Bolsa Família na alocação de recursos: uma análise considerando a presença de mulheres...

a) Pela alteração da renda domiciliar total e da renda relativa dos membros da família;

ou

b) Pela variação do conhecimento e das preferências dos membros da família, sobretudo devido às condicionalidades dos programas.

Nesse sentido, a mulher é o membro do domicílio mais afetado, pois, para cumprir as condicionalidades do programa, ela se insere na sociedade e, consequentemente, tem suas preferências modificadas. Isso ocorre quando ela leva o filho ao posto de saúde, vai ao banco receber o benefício ou no momento em que o filho passa a frequentar a escola e conhece novos produtos e adquire novas necessidades (Favero; Santos, 2014).

A literatura de políticas públicas mostra que programas de transferência de renda que concedem renda, preferencialmente às mulheres, tendem a aumentar a proporção da renda destinada ao consumo de alimentos. Djebbari (2005), Maluccio e Flores (2004), Baptistella (2012), Ferrario (2013) e Attanasio et al. (2012) são exemplos de trabalhos que demonstram essa tendência.

Com vistas a aumentar a eficácia de algumas políticas públicas, inclusive das políticas de combate à pobreza, tem-se argumentado que as mulheres se preocupam mais com a educação, a saúde e o bem-estar de suas famílias e filhos ou, simplesmente, que as mulheres gastam "melhor" (Pinheiro; Fontoura, 2007).

A literatura de avaliação de programas sociais possui vários trabalhos que avaliam como a introdução de programas de transferência de renda afetam as parcelas de dispêndio das famílias em países em desenvolvimento, como México, Colômbia e Nicarágua. Em geral, o interesse é verificar como o aumento da renda das mulheres (geralmente os benefícios são concedidos às mulheres) afeta as parcelas de dispêndio. Ressalta-se, entretanto, a inexistência de estudos que analisam a realocação da renda pelas famílias brasileiras quando estas recebem o incremento de renda proveniente do PBF, sobretudo considerando a perspectiva de gênero, conforme apontaram Pinheiro e Fontoura (2007).

Este trabalho pretende oferecer uma análise do efeito do PBF sobre o consumo domiciliar no Brasil. Especificamente, procura-se identificar em que medida o PBF alterou tanto o valor do dispêndio em cada categoria como a importância relativa de cada categoria (parcelas de dispêndio), de acordo com a presença de mulheres nos domicílios.

Além desta introdução, este trabalho é constituído por outras quatro seções. Na seção 1, apresenta-se o modelo teórico de alocação de recursos domésticos. Na seção 2, são descritas as metodologias empregadas para estimação do efeito do PBF sobre o consumo nos domicílios brasileiros e, na seção 3, são apresentados e discutidos os resultados encontrados. A última seção expõe as conclusões do trabalho. 


\section{Modelo de alocação de recursos domésticos}

Durante muitos anos, as preferências domésticas foram tratadas como sendo únicas dentro do domicílio. Assim, maximizava-se uma única função de utilidade para todo o domicílio (Becker, 1965; Gronau, 1997; Becker, 1991). Com isso, o domicílio era tratado como uma unidade homogênea, em que um único membro da família determinava ditatorial ou altruisticamente todas as alocações do domicílio. Essa maneira de abordar a alocação de renda dentro do domicílio foi denominada de Modelo Unitário.

No entanto, vários trabalhos, como Thomas (1993), Thomas e Chen (1994) e Angelucci e Attanasio (2013), rejeitaram esse modelo, porque, segundo eles, não refletiam a realidade intradomiciliar.

Atualmente, o modelo coletivo de alocação dos recursos domésticos é considerado mais adequado para explicar a forma como as famílias destinam a renda. Nele, as preferências de todos os membros da família são relevantes para a tomada de decisão. Ou seja, as preferências de cada um deles têm um peso na função de bem-estar do domicílio. Nesse sentido, o poder de cada um na tomada de decisão pode depender de diversos fatores. Por exemplo, é possível estabelecer que quanto maior for a renda de determinado indivíduo, maior será seu poder de barganha. Nesse caso, assume-se que a renda do membro da família é uma forma de medir seu poder de barganha.

Nos modelos coletivos, o nível de análise passa para o indivíduo, que possui preferências próprias e influência sobre os recursos. É a interação entre os indivíduos - seja cooperativa ou não cooperativa - que determinará o comportamento econômico da família, isto é, para onde serão alocados os recursos e quais bens serão adquiridos. Assim, os modelos coletivos se diferenciam dos unitários em duas grandes linhas: a) cada membro do domicílio tem sua própria função utilidade; e b) lazer e consumo não dependem apenas do total de recursos disponíveis, mas do controle de cada membro sobre os recursos.

Nos modelos coletivos que se baseiam na barganha cooperativa, o comportamento da família é visto como o resultado de um jogo de barganha, de forma que as alocações de recursos são o resultado de um processo no qual cada membro buscará alocar os recursos sobre os quais tem controle para os bens que mais valoriza (Pinheiro; Fontoura, 2007). Assim, os padrões de consumo familiar não dependem mais apenas da renda total mas também dos recursos controlados por cada um dos indivíduos.

Com isso, a seguir, considera-se um modelo baseado nos trabalhos de Chiappori ${ }^{2} \mathrm{e}$ utilizado por Thomas (1993), o qual ajuda a explicar como a variação da renda proveniente de programas de transferência de renda ${ }^{3}$ e, consequentemente, o aumento do poder de barganha

(2) Chiappori (1988), Browning et al. (1994) e Browning et al. (2006).

(3) Estes estudos têm como pressuposição que a renda do trabalho é endógena, determinada dentro do modelo, pois insere a variável lazer. Já a renda não proveniente do trabalho seria exógena e determinante da demanda de bens. Além disso, seria um instrumento válido para a renda total. 
Influência do Programa Bolsa Família na alocação de recursos: uma análise considerando a presença de mulheres...

da mulher dentro do domicílio afetam a demanda de bens. Esse modelo foi escolhido por considerar o efeito da renda não proveniente do trabalho e, especificamente, por ter sido empregado para demonstrar o efeito da renda oriunda de transferências governamentais sobre a alocação de recursos domésticos.

A renda não proveniente do trabalho pode ter as seguintes origens: rendimentos de ativos financeiros (caso a família possua ativos); transferências privadas (renda transferida de uma família para outra); e transferências públicas (renda transferida do governo).

As transferências públicas, por sua vez, podem ocorrer de três modos diferentes: pensão e aposentadoria da previdência pública; Benefício de Prestação Continuada (BPC); e programas sociais de transferência de Renda (sendo o de maior representatividade o Programa Bolsa Família - PBF, segundo Santos (2012)).

Neste trabalho, considera-se um modelo de comportamento familiar no qual o bemestar do domicílio, $\mathrm{W}$, depende da utilidade de cada membro do domicílio, $\mathrm{m}=1, \ldots, \mathrm{M}$; por sua vez, a utilidade de cada indivíduo, $\mathrm{U}_{\mathrm{M}}$, depende do consumo de todos os membros, $X_{\text {im }}, i=$ $1, \ldots, G$, bens e do lazer de cada indivíduo do domicílio, $1_{1}, \ldots, 1_{\mathrm{M}}$. Um conjunto de características específicas dos indivíduos e do domicílio, $\mu$, também pode afetar os gostos e, portanto, a utilidade, $U_{m}(X, l ; \mu)$.

Se um membro qualquer, n, é completamente egoísta ou tem preferências egoístas, então, todos os elementos de $X_{\text {im }}$ e $1_{m}, m \neq n$, terão peso zero na função de utilidade deste membro. No entanto, espera-se, em geral, que os membros do domicílio atribuam valor ao consumo dos outros membros do mesmo domicílio (Becker, 1991). Inclusive, existem evidências de que existe altruísmo até mesmo além dos parentes próximos (Altonji et al., 1993; Udry, 1990).

A função de bem-estar do domicílio é dada, então, por:

$$
W=W\left[U_{1}(X, l ; \mu), \ldots, U_{M}(X, l ; \mu)\right]
$$

que é maximizada, sujeita à seguinte restrição orçamentária domiciliar:

$$
p X=\sum_{m}^{M}\left[w_{m}\left(T-l_{m}\right)+y_{m}\right]
$$

em que p é um vetor de preços de todos os bens, $X$. O valor do tempo para cada indivíduo é $\mathrm{w}_{\mathrm{m}}$, e a renda total é dada pelo valor da renda do trabalho $w_{m}\left(T-l_{m}\right)$ mais a renda não proveniente do trabalho, $y_{\mathrm{m}}$. A renda do domicílio é simplesmente a soma da renda de todos os indivíduos.

Resolvendo o problema de maximização, a demanda domiciliar por cada bem i é dada por:

$$
X_{i}=\sum_{m}^{M} X_{i m}=g\left(p, y_{i}, \ldots, y_{M}, \mu\right)
$$

A demanda domiciliar depende de todos os preços, $\mathrm{p}$, das características do domicílio, $\mu$, e das rendas não provenientes do trabalho. 
O modelo domiciliar mais simples se verifica quando apenas um dos membros do domicílio define a alocação de recursos. Nesse caso, a função agregada $\mathrm{W}$ assume peso zero para todos os demais membros. Assim, a função de demanda não depende das rendas não provenientes do trabalho individuais, mas da sua soma:

$$
X_{i}=g\left(p, \sum_{m} y_{m}, \mu\right)
$$

Se todos os membros tiverem as mesmas preferências (os pesos serão iguais), ou se eles forem altruístas (atribuírem o mesmo valor ao consumo dos demais membros do domicílio), a demanda domiciliar dependerá da renda não proveniente do trabalho total. $\mathrm{Na}$ presença do altruísmo perfeito, as preferências comuns e os modelos ditatoriais são equivalentes, ao menos, em termos das suas previsões com relação ao impacto da renda individual sobre a demanda domiciliar de bens.

Assim, a mulher, ao receber um incremento de renda, como acontece quando ela se torna beneficiária do PBF, passa a ter, de acordo com esse modelo, mais influência na alocação da renda domiciliar, a não ser que ela seja totalmente altruísta e abdique do poder adquirido ou seu marido seja um ditador e não considere suas preferências na alocação da renda e tome posse do benefício, empregando-o onde lhe convier.

No entanto, assume-se que a regra de repartição da renda adotada pelo domicílio é eficiente segundo Pareto, ou seja, que maridos e mulheres possuem funções de utilidade diferentes, mas que, de alguma forma, escolhem uma alocação de recursos eficiente, isto é, em relação à qual nenhuma alternativa beneficiaria um dos membros da família sem prejudicar outro.

Portanto, a demanda de bens do domicílio não depende apenas do total da renda não proveniente do trabalho, mas também da sua distribuição dentro do domicílio:

$$
X_{i}=g\left(p, y_{1}, \ldots, y_{M}, \mu\right)
$$

Neste trabalho, testa-se se a renda proveniente de programas de transferência de renda tem o mesmo efeito sobre os dispêndios com as categorias de consumo e sobre as parcelas de dispêndio quando atribuída a homens e mulheres.

\section{Metodologia}

O Programa Bolsa Família (PBF) é resultado de um redesenho dos programas Bolsa Escola, Auxílio Gás e Programa de Erradicação do Trabalho Infantil (PETI).

A fim de se determinar o método de estimação do efeito dos programas de transferência de renda sobre a maneira como os domicílios brasileiros alocam seus recursos com as diferentes categorias de consumo, inicialmente, foram estabelecidos os critérios adotados para a definição do grupo de beneficiários de programas de transferências de renda (tratados) e do grupo que não recebe estes benefícios (não tratados). 
Influência do Programa Bolsa Família na alocação de recursos: uma análise considerando a presença de mulheres...

Para tanto, utilizaram-se os dados das POFs de 2002-2003 e de 2008-2009. Na POF de 2002-2003, os programas foram identificados no quadro 53 dos questionários por meio do código 3502 (PETI), 3601 e 3692 (Bolsa Escola) e 3901 (Auxílio Gás). Já na POF de 20082009, o PBF foi obtido no quadro 54 dos questionários mediante o código 1001.

Assim, é possível verificar o efeito dos programas de transferência de renda sobre os domicílios que receberam o benefício, tendo como base aqueles que não receberam, visto que não se pode observar o mesmo domicílio nas duas situações, beneficiário e não beneficiário.

Deste modo, foi atribuída uma probabilidade de participação a cada domicílio nos programas Bolsa Escola, Auxílio Gás ou PETI, em 2002, pela estimação de um propensity score, uma vez que nem todos os domicílios elegíveis ao programa recebem o benefício. Também calculou-se, separadamente, a probabilidade de participação dos domicílios no PBF, em 2008, pelo mesmo motivo. Com isso, o grupo de tratados na POF de 2002-2003 se refere àqueles que receberam transferência de renda de pelo menos um dos programas (Bolsa Escola, Auxílio Gás e PETI), e o grupo de tratados na POF de 2008-2009 diz respeito àqueles beneficiários do PBF.

Feito isso, foram pareados os domicílios para que se pudesse compará-los, utilizandose duas técnicas distintas de pareamento: Método do Vizinho Mais Próximo e Método de Kernel. Posteriormente, foi empregado o Método de Diferenças em Diferenças.

Espera-se que o montante destinado às categorias de consumo se eleve diante de um aumento de renda, porém, o quanto se destinará a cada uma pode ser variável de acordo com as preferências das famílias e do nível de consumo dos itens dessa categoria num período anterior ao benefício. Por outro lado, mesmo que haja um crescimento, em termos monetários, do dispêndio com determinada categoria, pode ocorrer que, relativamente às outras despesas de consumo, não aconteça uma variação significativa.

Assim, essa sequência de procedimentos foi adotada tanto para verificar o efeito da mudança da estrutura dos programas de transferência de renda, no Brasil, sobre o valor total despendido em cada uma das categorias de consumo, como também para averiguar o impacto sobre as parcelas de dispêndio com cada uma dessas categorias. A primeira análise permite verificar em que medida os gastos foram alterados, em termos absolutos, diante da introdução do PBF, ao longo das categorias de dispêndio. A segunda análise possibilita a inferência da variação da proporção dos gastos destinados a cada categoria de dispêndio em relação ao total das despesas de consumo.

\subsection{Identificação dos domicílios considerados na avaliação de impacto}

Levando-se em conta que a participação nos programas não ocorre de forma aleatória, pois existem critérios para a definição dos beneficiários, os grupos de tratamento e controle foram construídos em termos de características observáveis. Analisaram-se as características apresentadas pelo grupo de tratamento e, a partir de então, buscaram-se, no grupo de não tratados, unidades (domicílios) que apresentassem características semelhantes para minimizar o viés decorrente de diferenças tanto nas características observáveis quanto nas características 
não observáveis dos indivíduos. Assim, o grupo de tratamento foi definido com base no recebimento dos benefícios de um (ou mais) dos programas de transferência de renda, na POF de 2002-2003. E, sabendo que o principal critério para atribuição do programa é a renda per capita, o grupo de controle foi estabelecido de forma a apresentar a mesma renda per capita do grupo de tratamento, sendo que os valores referentes à renda dos domicílios beneficiários não incluem as transferências de renda dos programas Bolsa Família, Bolsa Escola, Auxílio Gás e PETI. Isto porque a renda analisada pelo governo para concessão do programa é aquela apresentada antes do recebimento do benefício. De modo que, após o beneficio, a renda dos beneficiários pode ser superior a daqueles não beneficiários, caso esteja próximo do limite superior.

A existência de domicílios que atendem aos critérios do programa, mas não são beneficiados, ocorre porque os programas de transferência de renda criados no Brasil não apresentam caráter universal, ou seja, não alcançam todos os domicílios/indivíduos elegíveis ou que preenchem os pré-requisitos do programa. Portanto, existem indivíduos com características semelhantes às dos beneficiários que não eram atendidos pelos Bolsa Escola, Auxílio Gás e Programa de Erradicação do Trabalho Infantil e que não são atendidos pelo PBF. Isto pode ocorrer por diversas razões, observáveis (renda per capita, localização geográfica, número de membros do domicílio, etc.) e não observáveis (habilidades, esforço, motivação), dando origem ao viés de seleção, que significa que só aqueles indivíduos mais propensos a participar se tornam beneficiários do programa.

No entanto, assumiu-se que os domicílios que apresentam as mesmas características observáveis possuem a mesma probabilidade de estarem nos grupos de tratamento e controle. Isso porque a lei que criou o PBF, Lei n. 10.836, em 9 de janeiro de 2004, estabelece que, para entrar no Programa Bolsa Família, a família precisa ter seus dados inseridos e atualizados no Cadastro Único ${ }^{4}$ para programas sociais do governo federal. Por sua vez, o Cadastro Único é realizado em nível municipal, sendo que cada município tem autonomia para definir a forma de cadastramento, que pode ser por meio da visita de um entrevistador à residência da família, do deslocamento da família até o local de cadastramento, ou mediante uma ação de mobilização social, que ocorre quando a gestão municipal do Cadastro Único realiza algum evento e solicita que as famílias compareçam ${ }^{5}$.

Existem na literatura diversos métodos para emparelhar beneficiários e não beneficiários, dentre os quais se destaca o Propensity Score Matching (PSM), que elimina o problema de viés de seleção nas características observáveis, que ocorre quando certos indivíduos têm mais chance de serem selecionados em uma amostra devido a características observáveis, tais como tamanho da família, sexo, idade, renda, etc.

(4) O Cadastro Único é regulamentado pelo Decreto n. 6.135/07, pelas Portarias n. 177, de 16 de junho de 2011, e n. 274, de 10 de outubro de 2011, e Instruções Normativas n. 1 e n. 2, de 26 de agosto de 2011, e as Instruções Normativas n. 3 e n. 4, de 14 de outubro de 2011.

(5) O município pode utilizar qualquer combinação dessas três formas de coleta de dados. 
Influência do Programa Bolsa Família na alocação de recursos: uma análise considerando a presença de mulheres...

Para obter o grupo de controle, utilizou-se um modelo probit, tendo a participação no programa como variável dependente binária e, como variáveis explicativas da seleção, todas as variáveis que, provavelmente, determinam a participação. Em seguida, foram gerados valores de probabilidade de participação a partir do modelo probit para todos os indivíduos da amostra de beneficiários e não beneficiários, sendo estes valores denominados "propensity scores". Com estes valores, escolhem-se, para cada participante do programa, alguns outros indivíduos para o pareamento, como os vizinhos mais próximos (Nearest neighbors Matching), e calcula-se a média da variável de interesse (gastos com as diferentes categorias de consumo e parcelas de dispêndios com as categorias de dispêndio) para estes e a diferença dessa média em relação ao valor da variável para o participante. Finalmente, calculam-se as médias das diferenças. Visto que a base de dados foi composta pelas POFs de 2002-2003 e de 2008-2009, subtraiu-se da média do consumo dos beneficiários do PBF a média do consumo dos não beneficiários (primeira diferença), em 2008. Desse valor, foi retirada a diferença que existia, em 2002, entre os beneficiários e não beneficiários do Bolsa Escola, Auxílio Gás e PETI (segunda diferença). Este método é denominado Diferenças em Diferenças, pois fornece o efeito do programa sobre os domicílios beneficiários em relação aos domićlíos não beneficiários (primeira diferença), depois da implantação do programa, considerando, assim, a diferença que já existia entre esses dois grupos antes do tratamento (segunda diferença).

A partir dos dados da POF de 2002-2003, quando o PBF ainda não tinha sido implementado, consideraram-se, como grupo de tratamento, aqueles domicílios beneficiários de um (ou mais) dos programas que antecederam o PBF, quais sejam: Bolsa Escola, Auxílio Gás e PETI. Já em 2008-2009, o grupo de tratamento foi composto pelos beneficiários do Programa Bolsa Família. O grupo de controle, por sua vez, compreende os domicílios que não recebiam nenhum desses programas, mas que possuíam renda per capita igual à dos beneficiários, dado que a renda per capita familiar é o principal critério de seleção desses programas.

Contudo, o que se verifica nos dados das duas POFs é que boa parte dos domicílios beneficiários apresenta renda familiar per capita superior ao limite legal estabelecido pelo MDS.

Com isso, o propensity score ${ }^{6}$ foi empregado para domicílios de dois grupos de renda $^{7}$. A primeira faixa de renda foi estabelecida de modo a estudar os domicílios beneficiários que possuíam renda per capita dentro do limite legal para receber o programa (renda per capita até $\mathrm{R} \$ 140,00)$. A segunda faixa de renda foi definida de forma que a amostra considerada na análise do impacto do PBF incluísse mais de $90 \%$ dos domicílios beneficiários do PBF (renda per capita entre $\mathrm{R} \$ 140,00$ e $\mathrm{R} \$ 400,00$ ). Portanto, os cerca de $10 \%$ restantes são outliers, possuem renda per capita acima de $\mathrm{R} \$ 400,00 \mathrm{e}$, portanto, foram excluídos da amostra.

(6) Para mais detalhes do método, consultar Rosenbaum e Rubin (1983).

(7) Em 2002-2003, o limite legal para se tornar beneficiário dos programas existentes era variável. Com isso, e devido ao fato de que deflacionando a renda per capita média para se tornar beneficiário dos três programas obtém-se um valor próximo dos valores considerados em 2008-2009, optou-se por considerar as mesmas faixas de renda em ambas as POFs. 
Neste trabalho, a estimação da probabilidade de ser beneficiário do PBF foi feita por meio de um modelo probit, da seguinte forma:

$$
P(D=1 \mid x)=\Phi\left(\beta_{0 i}+\beta_{i} \sum_{i=1}^{17} X_{i}\right)
$$

em que $\Phi$ é a função de distribuição normal padrão acumulada, e $\mathrm{X}_{\mathrm{i}}$ são as variáveis independentes que influenciam na probabilidade de participação e são descritas no Quadro 1. Se $\beta_{\mathrm{i}}$ for positivo, um aumento em $\mathrm{X}_{\mathrm{i}}$ aumentará a probabilidade de o domicílio receber o tratamento, caso contrário, um aumento em $\mathrm{X}_{\mathrm{i}}$ diminuirá a probabilidade de $\mathrm{Y}=1$.

A variável "anos de estudo da mulher" foi construída para captar o efeito da educação da mulher sobre o consumo, uma vez que, quando ela é a chefe do domicílio, a sua escolaridade é captada pela variável "anos de estudo". Assim, construíram-se os anos de estudo da mulher quando ela é a esposa no domicílio, ou seja, para os casos em que nos microdados estão definidos: SEXO - feminino e RELAÇÃO COM A PESSOA DE REFERÊNCIA DA UC cônjuge. Esta variável foi definida multiplicando-se uma variável binária (1, se a mulher não é chefe, e 0 , se a mulher é chefe) pela variável "anos de estudo da mulher". Este procedimento foi adotado para evitar repetição de informação quando a mulher é chefe; sendo assim, quando a mulher for chefe, o efeito de anos de estudo será captado pela variável "anos de estudo do chefe".

Quadro 1

Descrição das variáveis utilizadas na estimação do Propensity Score Matching

\begin{tabular}{|c|c|}
\hline Variável & Descrição \\
\hline Sexo & Variável binária para o sexo da pessoa de referência do domicílio (mulher=1) \\
\hline Crianças e/ou adolescentes & $\begin{array}{l}\text { Variável binária para a presença de indivíduos entre } 0 \text { e } 18 \text { anos de idade no domicílio } \\
(\text { presença }=1)\end{array}$ \\
\hline Adultos & $\begin{array}{l}\text { Variável binária para presença de indivíduos de } 19 \text { a } 59 \text { anos de idade no domicílio } \\
(\text { presença=1) }\end{array}$ \\
\hline Idosos & Variável binária para presença de indivíduos acima de 60 anos no domicílio (presença=1) \\
\hline Área urbana & Variável binária para localização geográfica do domicílio (urbano=1) \\
\hline Anos de estudo & Número de anos de estudo da pessoa de referência do domicílio \\
\hline Anos de estudo da mulher & Número de anos de estudo da mulher quando não é a pessoa de referência do domicílio \\
\hline Número de moradores & Número total de moradores do domicílio \\
\hline Aposentados & Variável binária para a presença de indivíduos aposentados no domicílio (presença=1) \\
\hline Cor & Variável binária para a cor da pele do chefe do domicílio (branco=1) \\
\hline Nordeste & $\begin{array}{l}\text { Variável binária com valor igual a } 1 \text { caso o domicílio esteja localizado na Região Nordeste } \\
\text { e } 0 \text {, caso contrário }\end{array}$ \\
\hline Sul & $\begin{array}{l}\text { Variável binária com valor igual a } 1 \text { caso o domicílio esteja localizado na Região Sul e } 0 \text {, } \\
\text { caso contrário }\end{array}$ \\
\hline Sudeste & $\begin{array}{l}\text { Variável binária com valor igual a } 1 \text { caso o domicílio esteja localizado na Região Sudeste } \\
\text { e zero, caso contrário }\end{array}$ \\
\hline Norte & $\begin{array}{l}\text { Variável binária com valor igual a } 1 \text {, caso o domicílio esteja localizado na Região Norte e } \\
0 \text {, caso contrário }\end{array}$ \\
\hline Renda per capita & $\begin{array}{l}\text { Renda total, em } \mathrm{R} \$ \text { de } 15 / 01 / 2009 \text {, da unidade de consumo principal, correspondente ao } \\
\text { rendimento bruto total mensal, descontados os valores referentes aos programas de } \\
\text { transferência de renda, e dividido pelo número total de moradores. }\end{array}$ \\
\hline
\end{tabular}

Fonte: Dados da pesquisa. 
Influência do Programa Bolsa Família na alocação de recursos: uma análise considerando a presença de mulheres...

Outra variável que demanda esclarecimento sobre sua forma de obtenção é a renda per capita. Ela é resultado da razão entre o rendimento monetário total e o número de moradores do domicílio, sendo que o rendimento monetário total é obtido por meio do somatório dos rendimentos brutos monetários mensais de todos os moradores do domicílio, provenientes do trabalho, de transferências e de outras rendas, acrescido da variação patrimonial, que compreende vendas de imóveis, recebimentos de heranças e o saldo positivo da movimentação financeira.

Realizado o propensity score, procedeu-se ao matching. Para tanto, optou-se por usar duas técnicas: métodos do vizinho mais próximo e do pareamento de Kernel, com o objetivo de verificar a robustez dos resultados ${ }^{8}$.

De acordo com Becker e Ichino (2002), no método de pareamento pelo vizinho mais próximo (NNM), para cada unidade tratada, é procurada uma unidade não tratada com o escore de propensão mais próximo.

Formalmente, considere que $\mathrm{p}_{\mathrm{t}} \mathrm{e} \mathrm{p}_{\mathrm{c}}$ denotam o escore de propensão das unidades tratadas e não tratadas, respectivamente. $O$ conjunto de unidades não tratadas pareadas com as unidades tratadas é dado por:

$$
C(i)=\min \left\|p_{t}-p_{c}\right\|
$$

Geralmente, C(i) é calculado com reposição, o que significa que um mesmo indivíduo não tratado pode ser pareado com mais de um indivíduo tratado. A vantagem do NNM é que, para cada unidade tratada, sempre é encontrado um par, não tratado, evitando a exclusão de observações tratadas. Entretanto, isto pode gerar pareamento de indivíduos com escores de propensão muito diferentes, pois o vizinho mais próximo pode não ser tão próximo. O método de Pareamento de Kernel oferece uma solução a este problema.

No método de Pareamento de Kernel (Kernel Matching - KM), todas as unidades tratadas são pareadas com a média ponderada de todos os controles. Os pesos são inversamente proporcionais à diferença entre o escore de propensão das unidades tratadas e não tratadas (Becker; Ichino, 2002).

Uma vez determinado o grupo de comparação por meio do matching, o efeito médio do programa pode ser obtido por meio do estimador de Diferenças em Diferenças (DD).

O método do pareamento pode ser combinado com o método de Diferenças em Diferenças (Menezes-Filho, 2012). Esta combinação faz com que algumas das hipóteses usadas em cada um dos métodos possam ser substituídas por hipóteses mais fracas. Khandker et al. (2010) afirmam também que, ao empregar o PSM antes do DD, estimadores mais eficientes são gerados, dado que reduz o viés de seleção nos observáveis.

(8) Estes métodos foram os mesmos usados por Silveira Neto (2010) e Fahel et al. (2013), por exemplo. 
Formalmente, o método que combina pareamento e o método de Diferenças em Diferenças estima o seguinte parâmetro:

$$
D_{t_{0}, t_{1}}=E\left[Y_{i t_{1}}^{1}-Y_{i t_{0}}^{0} \mid T_{i}=1, X_{i}\right]-E\left[Y_{i t_{1}}^{0}-Y_{i t_{0}}^{0} \mid T_{i}=0, X_{i}\right]
$$

em que $Y_{i t}^{d}$ representa o resultado no tempo t para o indivíduo i quando o seu status de tratamento é d.

\subsection{Fonte de dados}

Os dados utilizados neste trabalho foram retirados da Pesquisa de Orçamentos Familiares (POF), conduzida periodicamente pelo Instituto Brasileiro de Geografia e Estatística (IBGE).

Empregaram-se os dados das pesquisas 2002-2003 e 2008-2009, que entrevistaram 44.248 e 59.548 domicílios, respectivamente.

A data-base das informações de despesa e rendimento da POF de 2002-2003 é 15 de janeiro de 2003, e a da POF de 2008-2009, 15 de janeiro de 2009. Os valores monetários foram deflacionados pelo Índice Nacional de Preços ao Consumidor Amplo (IPCA) - 159 , a preços constantes de 15 de janeiro de 2009.

\subsection{Estimação do efeito do Programa Bolsa Família sobre o dispêndio com as categorias de consumo}

$\mathrm{O}$ modelo a ser estimado para verificar como o PBF afeta os dispêndios com as categorias de consumo $\left(Y_{i t}^{j}\right)$ consiste na estimação de 11 equações, dado que a POF divide as despesas de consumo em 11 categorias de consumo. Esses estimadores foram obtidos por meio de Seemingly Unrelated Regressions (SUR).

Este modelo pode ser representado da seguinte forma ${ }^{10}$ :

$$
Y_{i t}^{j}=\alpha_{i}+\eta D_{i t}+\zeta T_{t}+\beta D_{i t} T_{t}+\delta_{i} \sum X_{i t}^{k}+\varepsilon_{i t}^{j}
$$

em que: i representa o domicílio; $t=2002,2008$; $\mathrm{j}$ indica cada uma das 11 categorias de consumo. Portanto:

- $Y_{i t}^{j}$ é o dispêndio com a categoria de consumo j, no domicílio i e no tempo t.

- $\quad \mathrm{D}_{\mathrm{it}}$ é uma variável binária para o tratamento. Se o domicílio possui algum indivíduo beneficiário do $\mathrm{PBF}, \mathrm{D}_{\mathrm{it}}=1$. Caso contrário, $\mathrm{D}_{\mathrm{it}}=0$.

(9) O IPCA-15 situa o período de coleta de preços, aproximadamente, do dia 15 do mês anterior ao dia 15 do mês de referência. Além disso, abrange as famílias com rendimentos mensais compreendidos entre 1 (um) e 40 (quarenta) saláriosmínimos, qualquer que seja a fonte de rendimentos, e residentes nas áreas urbanas das regiões.

(10) Esta formulação é baseada em Angrist e Pischke (2008). 
Influência do Programa Bolsa Família na alocação de recursos: uma análise considerando a presença de mulheres...

- $T_{t}$ é a variável indicativa do tempo analisado, recebendo valor 1 para o ano de 2008 e 0 para 2002;

- $\varepsilon_{i t}^{j}$ é o termo de erro atribuído à categoria de consumo $\mathrm{j}$, no domicílio i e no tempo t.

As categorias de consumo consideradas foram as seguintes ${ }^{11}$ :

1) Alimentação: inclui as despesas com alimentação no domicílio (cereais, leguminosas e oleaginosas; farinhas, féculas e massas; tubérculos e raízes; açucares e derivados; legumes e verduras; frutas; carnes, vísceras e pescados; aves e ovos; leites e derivados; panificados; óleos e gorduras; bebidas e infusões; enlatados e conservas; sal e condimentos; alimentos preparados; e outros alimentos) e fora do domicílio (almoço e jantar; café, leite, café/leite, chocolate; sanduíches e salgados; refrigerantes e outras bebidas não alcoólicas; lanches; cervejas, chopes e outras bebidas alcoólicas; alimentação na escola; alimentação light e diet; e outros);

2) Habitação: inclui as despesas com aluguel, condomínio, serviços e taxas (telefone fixo; telefone celular; energia elétrica; pacote de TV, internet e telefone; gás doméstico; água; e esgoto), manutenção do lar, artigos de limpeza, mobiliários e artigos do lar, eletrodomésticos e conserto de artigos do lar;

3) Vestuário: inclui as despesas com roupa de homem, roupa de mulher, roupa de criança, calçados e apetrechos, joias e bijuterias, tecidos e armarinhos;

4) Transporte: inclui as despesas com transporte urbano, gasolina (veículo próprio), álcool (veículo próprio), manutenção e acessórios, aquisição de veículos, viagens esporádicas, outras;

5) Higiene e cuidados pessoais: inclui as despesas com perfume, produtos para cabelo, sabonete, instrumentos e produtos de uso pessoal;

6) Assistência à saúde: inclui as despesas com remédios, plano/seguro de saúde, consulta e tratamento dentário, consulta médica, tratamento médico e ambulatorial, serviços de cirurgia, hospitalização, exames diversos, material de tratamento, outras;

7) Educação: inclui as despesas com cursos regulares, curso superior, outros cursos e atividades, livros didáticos e revistas técnicas, artigos escolares, outras;

8) Recreação e cultura: inclui as despesas com brinquedos e jogos, celular e acessórios, periódicos, livros e revistas não didáticos, recreação e esportes, outras;

9) Fumo: inclui as despesas com cigarro, isqueiro, charuto, cigarrilha, fumo desfiado, fumo desfiado para cigarro, fumo desfiado para cachimbo, fósforo, piteira, fluido de isqueiro, gás de isqueiro, pedra de isqueiro, fumo de rolo, rape, cigarro de palha, palha para

(11) A composição de cada categoria é a mesma considerada pelo IBGE na POF. 
Mirian Aparecida Rocha, Leonardo Bornacki de Mattos, Alexandre Bragança Coelho

cigarro, papel de cigarro, maconha, cigarro de maconha, cocaína, lança-perfume, dentre outros;

10) Serviços pessoais: inclui as despesas com cabeleireiro, manicuro e pedicuro, consertos de artigos pessoais, outras; e

11) Despesas diversas: inclui as despesas com jogos e apostas, comunicação, cerimônias e festas, serviços profissionais, imóveis de uso ocasional, outras.

O valor estimado de $\eta$ corresponde às diferenças existentes entre o grupo de tratamento e controle em 2002 e que, portanto, não se devem ao PBF, ou seja, são as diferenças naturais entre os dois grupos.

Já o valor estimado de $\zeta$ corresponde às alterações ocorridas no dispêndio com determinada categoria de consumo ao longo do tempo, que ocorreriam independentemente da introdução do PBF.

Dessa forma, o parâmetro $\beta$, que é o coeficiente do termo de interação entre as variáveis binárias $D_{i t}$ e $T_{t}$, mede a mudança no dispêndio com determinada categoria de consumo devido ao PBF, dado que essa política gera impactos apenas no grupo de tratamento. Assim, $\beta$ é o estimador de diferenças em diferenças detalhado na equação (10).

Além disso, $\mathrm{X}_{\mathrm{it}}$ é o conjunto das $\mathrm{k}$ variáveis de controle relacionadas às características dos indivíduos e dos domicílios em que estão inseridos. Esse conjunto compreende as variáveis detalhadas no Quadro 1 da seção anterior.

Para a construção dessas categorias de consumo, foram utilizados os tradutores de tabelas disponibilizados pelo IBGE para cada uma das POFs, visto que em cada uma delas os bens considerados na agregação são distintos. Os tradutores de tabelas fornecem os códigos dos bens e serviços a serem incluídos em cada categoria.

Além disso, para garantir que os bens e serviços fossem agregados de forma correta, os valores foram comparados com os fornecidos pelo IBGE em suas publicações. Esta comparação se faz necessária dada a complexidade dos dados. Por exemplo, a amostra da POF 2008-2009 é formada por 55.970 domicílios, incluindo 56.091 famílias ou "unidades de consumo". Considerando os fatores de expansão ${ }^{12}$, essa amostra representa uma população de 57.816.604 famílias, com 190.519.297 pessoas.

A dificuldade principal se deu pelo fato de que, para computar o valor médio do consumo com cada bem no período analisado, foi necessário considerar: o fator de expansão atribuído a ele, para que esse valor seja representativo em termos regionais e nacional; o número de unidades de consumo que compõe o domicílio; e os diversos fatores de anualização,

(12) Cada domicílio pertencente à amostra da POF representa um determinado número de domicílios particulares permanentes da população (universo), de onde esta amostra foi selecionada. Com isso, a cada domicílio da amostra, está associado um peso amostral ou fator de expansão, que, atribuído às características investigadas pela pesquisa, permite a obtenção de estimativas das quantidades de interesse para o universo da pesquisa (IBGE, 2010). 
Influência do Programa Bolsa Família na alocação de recursos: uma análise considerando a presença de mulheres...

uma vez que os dados foram coletados considerando diversos períodos de referência $(7,30,90$ e 360 dias), de acordo com a frequência e o valor de aquisição, de modo a ampliar a capacidade do informante para fornecer os valores das aquisições realizadas e as demais informações a elas associadas. Outros fatores relevantes são o deflator do item e o número de meses em que ele foi adquirido durante o ano.

\subsection{Estimação do efeito do Programa Bolsa Família sobre as parcelas de dispêndio}

O modelo econométrico proposto para representar as equações das parcelas de dispêndio, assim como as despesas com as categorias de dispêndio, foi um sistema de equações aparentemente não relacionadas, dado que existe uma relação entre as diferentes categorias de consumo, bem como entre as parcelas de dispêndio.

A especificação geral do sistema de regressões aparentemente não relacionadas, conhecido na literatura como modelo Seemingly Unrelated Regressions (SUR), incluindo a hipótese de autocorrelação dos resíduos, é a seguinte:

$$
\begin{gathered}
Y_{i t}^{j}=\alpha_{i}+\eta D_{i t}+\zeta T_{t}+\beta D_{i t} T_{t}+\delta_{i} \sum X_{i t}^{k}+\varepsilon_{i t}^{j} \\
\varepsilon_{i t}{ }^{j}=\rho_{i 1} \varepsilon_{i t-1}{ }^{j}
\end{gathered}
$$

$t=2002,2008 ; i=1,2, \ldots, N ; \mathrm{j}$ indica cada uma das 10 diferentes categorias de consumo ${ }^{13}$

$$
\begin{gathered}
E\left(\varepsilon_{t} \varepsilon^{\prime}{ }_{t}\right)=\Omega ; \varepsilon^{\prime}{ }_{t}=\left(\varepsilon_{1 t}, \varepsilon_{2 t}, \ldots, \varepsilon_{N t}\right) \\
u_{i t}{ }^{j} \sim N\left(0, \sigma^{2}\right)
\end{gathered}
$$

em que:

$Y_{i t}^{j}$ é a parcela de dispêndio com cada categoria de consumo j, no domicílio i e no tempo t. A parcela de dispêndio é definida como a razão entre o dispêndio com a categoria j e o total da despesa de consumo.

$\varepsilon_{i t}^{j}$ são os resíduos, geralmente assumidos como independentes, mas que, neste caso, podem apresentar correlação contemporânea entre as equações.

$X_{i t}^{k}$ é o conjunto das $\mathrm{k}$ variáveis de controle relacionadas às características dos indivíduos e dos domicílios. Esse conjunto compreende as variáveis detalhadas no Quadro 1.

Aqui, também, o parâmetro de interesse é o $\beta$, pois fornece o estimador de DD, que mede a mudança provocada pelo PBF nas parcelas de dispêndio.

(13) A categoria fumo foi excluída da estimação por representar a menor proporção dos gastos das famílias e estimada de forma residual. 
Mirian Aparecida Rocha, Leonardo Bornacki de Mattos, Alexandre Bragança Coelho

\section{Resultados e discussão}

\subsection{Probabilidade de participação no Programa Bolsa Família}

O Propensity Score Matching (PSM) foi empregado a fim de estimar a probabilidade de participação de cada um dos domicílios no programa.

A Tabela A1 mostra os resultados do propensity score para os domicílios mistos com renda per capita de até $\mathrm{R} \$ 140,00$. Ressalta-se que o propensity score foi calculado separadamente para os domicílios das POFs de 2002-2003 e de 2008-2009. Com isso, a apresentação dos resultados do probit, na Tabela A1, visa a mostrar, de modo geral, como se comporta a probabilidade de participação dos domicílios nos programas de transferência de renda.

Verifica-se que, em ambos os anos, as variáveis que foram significativas para explicar a probabilidade foram: presença de crianças e/ou adolescentes, presença de idosos, área urbana, Região Norte, Região Nordeste, anos de estudo do chefe, número de moradores e renda per capita.

Com base na Tabela A2, pode-se afirmar que todas as variáveis apresentaram redução do viés após o matching, sendo que, das 14 variáveis analisadas, apenas quatro apresentaram redução do viés inferior a 70\%, quais sejam, presença de idosos (68\%), anos de estudo da mulher $(48,5 \%)$, presença de aposentados $(36,6 \%)$ e renda per capita $(49,2 \%)$. Além disso, de acordo com o teste $t$, antes do matching, havia diferença entre as médias dos grupos de tratamento e de controle para todas as variáveis. Contudo, depois do matching, somente as variáveis presença de idosos, anos de estudo do chefe, anos de estudo da mulher, presença de aposentados, Região Sudeste e renda per capita apresentaram diferença de médias. Portanto, pode-se considerar os grupos de controle e tratamento semelhantes e realizar a avaliação de impacto.

\subsection{Alocação de recursos nos domicílios beneficiários do PBF}

Com o intuito de verificar o comportamento dos beneficiários e não beneficiários do PBF em relação ao consumo, verifica-se, na Tabela 1, como eram os gastos per capita em cada uma das categorias de consumo, bem como o quanto representavam nas despesas de consumo das famílias, em 2002 e em 2008.

Para todas as categorias de consumo, os gastos per capita dos domicílios não beneficiários foram maiores do que os gastos per capita dos domicílios beneficiários, respeitadas as faixas de renda. Em termos absolutos, as categorias para as quais os não beneficiários destinam um montante maior da renda são habitação, alimentação e transporte, exatamente as mais expressivas no orçamento doméstico brasileiro. 
Influência do Programa Bolsa Família na alocação de recursos: uma análise considerando a presença de mulheres...

Tabela 1

Média (em R\$) dos gastos mensais per capita dos domicílios beneficiários e não beneficiários do Programa Bolsa Família, com as categorias de consumo, em 2002 e em 2008.

\begin{tabular}{|c|c|c|c|c|c|c|c|c|}
\hline \multirow{3}{*}{ Categorias } & \multicolumn{4}{|c|}{ Beneficiários } & \multicolumn{4}{|c|}{ Não Beneficiários } \\
\hline & \multicolumn{2}{|c|}{$\begin{array}{c}\text { Renda per capita } \\
\text { até } \mathrm{R} \$ 140,00\end{array}$} & \multicolumn{2}{|c|}{$\begin{array}{c}\text { Renda per capita } \\
\text { entre } \mathrm{R} \$ 140,00 \mathrm{e} \\
\mathrm{R} \$ 400,00\end{array}$} & \multicolumn{2}{|c|}{$\begin{array}{c}\text { Renda per capita } \\
\text { até } \mathrm{R} \$ 140,00\end{array}$} & \multicolumn{2}{|c|}{$\begin{array}{c}\text { Renda per capita } \\
\text { entre } R \$ 140,00 \text { e } \\
R \$ 400,00\end{array}$} \\
\hline & 2002 & 2008 & 2002 & 2008 & 2002 & 2008 & 2002 & 2008 \\
\hline Despesas de consumo & 107,64 & 118,35 & 221,31 & 218,82 & 155,53 & 184,30 & 288,36 & 278,99 \\
\hline Alimentação & 47,38 & 48,13 & 78,15 & 75,93 & 60,36 & 57,17 & 90,97 & 83,19 \\
\hline Despesas diversas & 1,71 & 1,97 & 5,32 & 5,18 & 3,20 & 4,59 & 8,33 & 7,17 \\
\hline Educação & 1,70 & 1,52 & 3,53 & 3,30 & 2,00 & 2,59 & 5,03 & 4,85 \\
\hline Fumo & 1,37 & 1,30 & 2,51 & 2,19 & 2,44 & 2,57 & 4,11 & 3,28 \\
\hline Habitação & 24,29 & 29,61 & 53,28 & 55,27 & 42,22 & 52,55 & 79,58 & 79,39 \\
\hline Higiene & 3,97 & 4,61 & 7,45 & 9,53 & 4,91 & 6,44 & 8,81 & 9,95 \\
\hline Recreação e cultura & 1,03 & 1,35 & 3,54 & 4,16 & 1,87 & 2,99 & 4,81 & 4,78 \\
\hline Saúde & 5,31 & 6,62 & 14,84 & 11,93 & 8,5 & 12,54 & 21,58 & 18,19 \\
\hline Serviços pessoais & 0,85 & 1,17 & 2,03 & 2,53 & 1,30 & 1,96 & 3,35 & 3,44 \\
\hline Transporte & 12,61 & 13,70 & 32,95 & 31,32 & 18,64 & 29,09 & 42,17 & 46,32 \\
\hline Vestuário & 7,41 & 8,35 & 17,71 & 17,47 & 10,09 & 11,82 & 19,61 & 18,43 \\
\hline Número de domicílios & 3536 & 5098 & 1615 & 3498 & 9812 & 4914 & 16012 & 14976 \\
\hline$\%$ dos domicílios & 65,04 & 55,06 & 29,70 & 37,78 & & & & \\
\hline
\end{tabular}

Notas: ${ }^{(1)}$ Valores em R $\$$ e a preços constantes de 15/01/2009, deflacionados pelo IPCA-15.

(2) Os valores referentes à renda dos domicílios beneficiários não incluem as transferências de renda dos programas Bolsa Família, Bolsa Escola, Auxílio Gás e PETI.

Fonte: Dados da pesquisa.

De modo geral, as despesas per capita de consumo reduziram nos domicílios com renda per capita entre $\mathrm{R} \$ 140,00$ e $\mathrm{R} \$ 400,00$ e aumentaram nos com renda per capita até $\mathrm{R} \$ 140,00$. Contudo, os gastos com alimentação caíram em quase todos os cenários. Os dispêndios per capita com as categorias educação, fumo, habitação, higiene, recreação e serviços pessoais variaram no mesmo sentido para os beneficiários, independente da faixa de renda. Já nos domicílios não beneficiários, o dispêndio per capita variou no mesmo sentido apenas nas categorias alimentação, higiene, serviços pessoais e transporte.

Isso demonstra um comportamento distinto dos domicílios beneficiários e dos não beneficiários, ao longo do tempo e entre as faixas de renda, o que exige um maior detalhamento dos determinantes dessa ausência de padrão entre esses grupos.

Destaca-se, também, que houve uma redução considerável do número de não beneficiários, em comparação ao de beneficiários, entre 2002 e 2008, fazendo com que o grupo de não beneficiários fosse menor, em 2008, para ambas as faixas de renda. Isso indica que o PBF está alcançando, principalmente, os mais pobres, apesar de não ter conseguido eliminálos. 
Para verificar se o PBF teve um impacto sobre o valor monetário destinado ao consumo pelos domicílios com homens e mulheres, adotou-se a mesma metodologia proposta por Thomas e Chen (1994). Foram separados os domicílios mistos, que têm homens e mulheres adultos, dos que têm somente mulheres adultas, sendo considerados adultos os membros com idade igual ou superior a 18 anos. Feito isso, estimou-se a equação (9) para os domicílios mistos e depois para os femininos.

Considerando que a mulher, tradicionalmente, tem maior contato com os filhos e com o cotidiano da casa (Suárez; Linbardoni, 2007), é provável que tenha preferências diferentes das dos homens e que, ao aumentar o poder de barganha na tomada de decisão, no momento da alocação dos recursos, a demanda das categorias de consumo se altere entre os beneficiários do PBF nos domicílios mistos, onde ocorre uma negociação com relação à alocação. Por outro lado, nos domicílios com apenas mulheres adultas, em que não havia homem para negociar com elas, nenhuma variação, em termos relativos, era esperada, pois as decisões de alocação já eram tomadas pelas mulheres.

De modo geral, como pode ser visto na Tabela $2^{14}$, o impacto do PBF sobre os dispêndios nos domicílios mistos e nos domicílios femininos foi distinto, conforme a significância dos estimadores de DD.

Cabe destacar que a média do aumento do valor do benefício para os domicílios mistos foi de $\mathrm{R} \$ 51,99$ e, para os femininos, de $\mathrm{R} \$ 49,15$. Portanto, os domicílios femininos destinaram a totalidade da variação do benefício para as despesas de consumo, uma vez que estas se ampliaram em $\mathrm{R} \$ 51,08$.

Nos domicílios mistos, a única categoria de dispêndio que não sofreu variação significativa diante do PBF foi a do fumo, empregando o NNM. Logo, os domicílios que possuem homens e mulheres adultos e que são beneficiários do PBF não destinam montante significativo da transferência para a aquisição de bens relacionados à categoria fumo, o que pode denotar certa qualidade na destinação dos gastos do benefício, mesmo porque, de acordo com os resultados, os domicílios ampliaram, sobretudo, os gastos com habitação e alimentação.

Os domicílios mistos diluíram o benefício, destinando-o a diversas categorias, embora o principal aumento também tenha se dado na categoria habitação.

Contudo, observa-se que, nos domicílios femininos, o aumento dos gastos com habitação representou mais de $50 \%$ do aumento dos gastos com despesas de consumo.

$\mathrm{O}$ equilíbrio de forças entre homens e mulheres se evidencia na medida em que se verifica que o PBF alterou, significativamente, os gastos com determinada categoria de consumo nos domicílios mistos, enquanto, nos domicílios femininos, o PBF não gerou variação significativa no montante destinado a essa categoria.

(14) Como exercício de robustez, o efeito do PBF para esses grupos também foi medido considerando-se adultos os membros do domicílio com idade maior ou igual a 15 anos. Os resultados obtidos, apresentados no Anexo, na Tabela A3, são semelhantes aos apresentados na Tabela 2. 
Influência do Programa Bolsa Família na alocação de recursos: uma análise considerando a presença de mulheres...

Tabela 2

Impacto do PBF sobre os dispêndios em domicílios mistos e em femininos, no período 2002-2008, Brasil

\begin{tabular}{|c|c|c|c|c|}
\hline \multirow{2}{*}{ Categorias } & \multicolumn{2}{|c|}{ Domicílios mistos } & \multicolumn{2}{|c|}{ Domicílios com apenas mulheres } \\
\hline & NNM & KM & NNM & KM \\
\hline \multirow{2}{*}{ Despesas de consumo } & $31,01 * * *$ & $34,28 * * *$ & $35,40 * * *$ & $51,08 * * *$ \\
\hline & $(3,30)$ & $(2,06)$ & $(10,37)$ & $(7,27)$ \\
\hline \multirow{2}{*}{ Alimentação } & $6,03 * * *$ & $6,42 * * *$ & $8,30 \mathrm{NS}$ & $13,73 * * *$ \\
\hline & $(1,58)$ & $(1,10)$ & $(5,06)$ & $(3,06)$ \\
\hline \multirow{2}{*}{ Despesas diversas } & $1,32 * * *$ & $1,16 * * *$ & $0,50 \mathrm{NS}$ & $0,94 * *$ \\
\hline & $(0,32)$ & $(0,15)$ & $(1,27)$ & $(0,45)$ \\
\hline \multirow{2}{*}{ Educação } & $0,75 * * *$ & $0,45 * * *$ & $0,99 * *$ & $0,92 * * *$ \\
\hline & $(0,17)$ & $(0,09)$ & $(0,42)$ & $(0,20)$ \\
\hline \multirow{2}{*}{ Fumo } & $0,19 \mathrm{NS}$ & $0,32 * * *$ & $0,37 \mathrm{NS}$ & $0,61 * * *$ \\
\hline & $(0,15)$ & $(0,10)$ & $(0,41)$ & $(0,17)$ \\
\hline \multirow{2}{*}{ Habitação } & $10,00 * * *$ & $11,51 * * *$ & $20,44 * * *$ & $21,49 * * *$ \\
\hline & $(1,15)$ & $(0,64)$ & $(5,32)$ & $(4,65)$ \\
\hline \multirow{2}{*}{ Higiene } & $1,19 * * *$ & $1,13 * * *$ & $0,88 \mathrm{NS}$ & $1,20 * *$ \\
\hline & $(0,25)$ & $(0,15)$ & $(0,83)$ & $(0,59)$ \\
\hline \multirow{2}{*}{ Recreação } & $0,82 * * *$ & $0,74 * * *$ & $0,61 \mathrm{NS}$ & $1,01 * * *$ \\
\hline & $(0,11)$ & $(0,07)$ & $(0,54)$ & $(0,33)$ \\
\hline \multirow{2}{*}{ Saúde } & $3,47 * * *$ & $3,46 * * *$ & $1,09 \mathrm{NS}$ & $2,75 * * *$ \\
\hline & $(0,48)$ & $(0,33)$ & $(1,24)$ & $(0,85)$ \\
\hline \multirow{2}{*}{ Serviços pessoais } & $0,58 * * *$ & $0,50 * * *$ & $0,34 \mathrm{NS}$ & $0,79 * * *$ \\
\hline & $(0,08)$ & $(0,05)$ & $(0,23)$ & $(0,17)$ \\
\hline \multirow{2}{*}{ Transporte } & $4,17 * * *$ & $5,80 * * *$ & $-1,98 \mathrm{NS}$ & $3,63 * * *$ \\
\hline & $(1,25)$ & $(0,82)$ & $(1,72)$ & $(1,13)$ \\
\hline \multirow{2}{*}{ Vestuário } & $2,49 * * *$ & $2,77 * * *$ & $3,86^{* * *}$ & $4,00 * * *$ \\
\hline & $(0,38)$ & $(0,24)$ & $(1,12)$ & $(0,70)$ \\
\hline N. de observações & 7274 & 7274 & 1228 & 1228 \\
\hline
\end{tabular}

***significativo a $1 \%$. **significativo a $5 \%$. *significativo a $10 \%$. NS: Não Significativo.

Os valores entre parênteses se referem aos erros-padrão.

Notas:

(1) Valores em $\mathrm{R} \$$ e a preços constantes de 15/01/2009, deflacionados pelo IPCA-15.

(2) Os valores referentes à renda dos domicílios beneficiários não incluem as transferências de renda dos programas Bolsa Família, Bolsa Escola, Auxílio Gás e PETI.

Fonte: Resultados da pesquisa.

Por outro lado, ao destinar renda para os domicílios femininos, o PBF fez com que eles passassem a consumir mais em itens relacionados à educação, habitação e vestuário. O que pode ter contribuído para que esses domicílios designassem seus recursos para essas categorias de bens é que, provavelmente, eles já alocavam a proporção desejada de renda para as demais categorias, podendo, assim, com o aumento da renda, priorizar outras necessidades.

Ademais, o PBF pode ter colaborado para que os domicílios elevassem seu consumo na categoria saúde, devido à condicionalidade de saúde, bem como às palestras ministradas 
Mirian Aparecida Rocha, Leonardo Bornacki de Mattos, Alexandre Bragança Coelho

para as beneficiárias pelos Centros de Referência de Assistência Social (CRAS), que atuam oferecendo serviços de assistência social às famílias e aos indivíduos em situação de vulnerabilidade social e compõem a rede de proteção social do País; com isso, acabam por criar demandas nos domicílios ao ampliar seu conhecimento sobre cuidados com a saúde.

Nesse sentido, ao tomar consciência do quão importante é o cuidado da sua saúde e da de seus filhos, e diante da falta de oferta de serviços de saúde adequados pela rede pública (ou de acesso a eles), as mulheres passaram a alocar um montante maior de recursos para bens da categoria saúde, sobretudo, ao se considerar as condições sanitárias às quais esses domicílios estão submetidos.

Nota-se que o volume de recursos destinados pelos domicílios mistos para a saúde se elevou em $\mathrm{R} \$ 3,47$, enquanto que, nos domicílios femininos, esse valor não foi significativo. Esta diferença pode ser atribuída ao fato de haver uma barganha entre homens e mulheres, nos domicílios mistos, no momento de alocar a renda. Nos femininos, as mulheres alocam o valor que lhes aprouver. Nesse caso, conclui-se que os homens apresentaram uma maior preferência por bens dessa categoria.

Se assumirmos que a influência da mulher se dá sobre o valor destinado a cada categoria e, portanto, que o PBF conferiu maior poder de barganha às mulheres nos casos em que os domicílios mistos destinaram um valor significativo para determinada categoria, enquanto os domicílios femininos não apresentaram variação significativa, então, considerando o NNM, o aumento do poder da mulher foi determinante na alocação da renda do PBF para alimentação, educação, higiene, recreação, saúde, serviços pessoais e transporte.

\subsection{Alteração nas parcelas de dispêndio das famílias brasileiras diante do PBF}

De maneira similar ao que ocorreu com os dispêndios com as categorias de consumo, esperava-se, com base no modelo coletivo de alocação de recursos domésticos, que o aumento de renda destinado às mulheres, promovido pelo PBF, fizesse com que a alocação dos recursos nas parcelas de dispêndio se alterasse apenas nos domicílios mistos, onde há uma negociação entre homens e mulheres no momento de alocar a renda.

Nesse caso, se a mulher tiver preferência por alimentos, por exemplo, o crescimento da parcela alimentação reflete o aumento do poder de barganha da mulher na alocação dos recursos domésticos. Com base no trabalho de Schady e Rosero (2008), esperava-se que a parcela alimentação fosse maior para os domicílios beneficiários do PBF que possuíssem homens e mulheres.

Verifica-se, na Tabela 3, a parcela de dispêndios per capita dos beneficiários e não beneficiários do PBF, em 2002 e em 2008, com as diferentes categorias de consumo. 
Influência do Programa Bolsa Família na alocação de recursos: uma análise considerando a presença de mulheres...

Tabela 3

Parcela de dispêndios mensais per capita dos domicílios beneficiários e não beneficiários do Programa Bolsa Família, com as categorias de consumo, em 2002 e em 2008

\begin{tabular}{|c|c|c|c|c|c|c|c|c|}
\hline \multirow{3}{*}{ Categorias } & \multicolumn{4}{|c|}{ Beneficiários } & \multicolumn{4}{|c|}{ Não Beneficiários } \\
\hline & \multicolumn{2}{|c|}{$\begin{array}{c}\text { Renda per capita } \\
\text { até } \mathrm{R} \$ 140,00\end{array}$} & \multicolumn{2}{|c|}{$\begin{array}{c}\text { Renda per capita } \\
\text { entre } R \$ 140,00 \text { e } \\
\text { R } \$ 400,00\end{array}$} & \multicolumn{2}{|c|}{$\begin{array}{c}\text { Renda per capita } \\
\text { até } \mathrm{R} \$ 140,00\end{array}$} & \multicolumn{2}{|c|}{$\begin{array}{c}\text { Renda per capita } \\
\text { entre } \mathrm{R} \$ 140,00 \text { e } \\
\mathrm{R} \$ 400,00\end{array}$} \\
\hline & 2002 & 2008 & 2002 & 2008 & 2002 & 2008 & 2002 & 2008 \\
\hline Despesas de consumo & 1,0000 & 1,0000 & 1,0000 & 1,0000 & 1,0000 & 1,0000 & 1,0000 & 1,0000 \\
\hline Alimentação & 0,4402 & 0,4067 & 0,3531 & 0,3470 & 0,3881 & 0,3102 & 0,3155 & 0,2982 \\
\hline Despesas diversas & 0,0159 & 0,0166 & 0,0240 & 0,0237 & 0,0206 & 0,0249 & 0,0289 & 0,0257 \\
\hline Educação & 0,0158 & 0,0128 & 0,0160 & 0,0151 & 0,0129 & 0,0141 & 0,0174 & 0,0174 \\
\hline Fumo & 0,0127 & 0,0110 & 0,0113 & 0,0100 & 0,0157 & 0,0139 & 0,0143 & 0,0118 \\
\hline Habitação & 0,2257 & 0,2502 & 0,2407 & 0,2526 & 0,2715 & 0,2851 & 0,2760 & 0,2846 \\
\hline Higiene & 0,0369 & 0,0390 & 0,0337 & 0,0436 & 0,0316 & 0,0349 & 0,0306 & 0,0357 \\
\hline Recreação e cultura & 0,0096 & 0,0114 & 0,0160 & 0,0190 & 0,0120 & 0,0162 & 0,0167 & 0,0171 \\
\hline Saúde & 0,0493 & 0,0559 & 0,0671 & 0,0545 & 0,0547 & 0,0680 & 0,0748 & 0,0652 \\
\hline Serviços pessoais & 0,0079 & 0,0099 & 0,0092 & 0,0116 & 0,0084 & 0,0106 & 0,0116 & 0,0123 \\
\hline Transporte & 0,1171 & 0,1158 & 0,1489 & 0,1431 & 0,1198 & 0,1578 & 0,1462 & 0,1660 \\
\hline Vestuário & 0,0688 & 0,0706 & 0,0800 & 0,0798 & 0,0649 & 0,0641 & 0,0680 & 0,0661 \\
\hline Número de domicílios & 3536 & 5098 & 1615 & 3498 & 9812 & 4914 & 16012 & 14976 \\
\hline
\end{tabular}

Fonte: Dados da pesquisa.

Para todas as faixas de renda, tanto para beneficiários quanto não beneficiários, notase que as parcelas mais representativas da despesa de consumo são com alimentação, habitação e transporte, respectivamente.

A parcela de dispêndio com alimentação é maior entre os beneficiários do PBF, ou seja, eles destinam um percentual maior da renda para alimentação do que aqueles que não recebem o benefício. Observa-se também que houve uma queda da parcela de dispêndio com alimentação, entre 2002 e 2008, para ambos os grupos, beneficiários e não beneficiários, nas duas faixas de renda consideradas.

O inverso se verifica na categoria habitação: os beneficiários destinam uma parcela menor da renda para habitação do que os não beneficiários. Para ambos os grupos analisados, nas duas faixas de renda, observou-se, de 2002 para 2008, aumento da parcela destinada à despesa com habitação.

$\mathrm{Na}$ categoria transporte, os beneficiários, em ambas faixas de renda analisadas, praticamente não alteram as parcelas de dispêndio entre os períodos analisados. Os não beneficiários, entretanto, elevaram a parcela de dispêndio com transporte. 
Na Tabela 4, encontram-se os resultados do efeito do PBF sobre a alocação dos recursos domésticos nas parcelas de dispêndios para domicílios em que se verifica a presença de mulheres e homens adultos e domicílios com apenas mulheres.

Tabela 4

Impacto do PBF sobre as parcelas de dispêndio dos domicílios mistos e dos femininos ${ }^{15}$

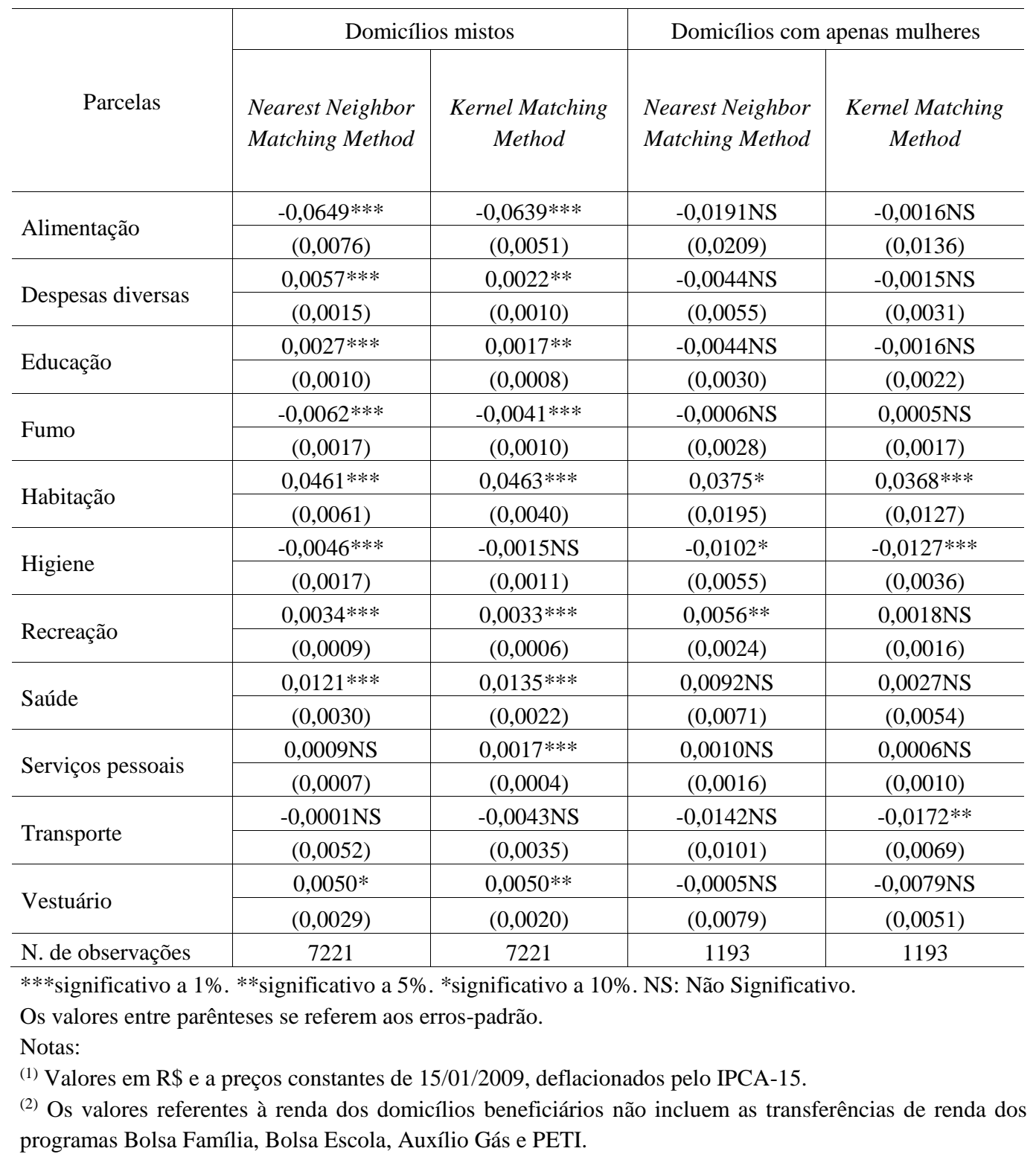

(15) Como exercício de robustez, o efeito do PBF para esses grupos também foi medido considerando-se adultos os membros do domicílio com idade maior ou igual a 15 anos. Os resultados obtidos, apresentados no Anexo, na Tabela A4, são semelhantes aos apresentados na Tabela 4. 
Influência do Programa Bolsa Família na alocação de recursos: uma análise considerando a presença de mulheres...

Fonte: Resultados da pesquisa.

Nota-se que, nos domicílios em que não existiam homens, e, portanto, não havia negociação para alocar os recursos, houve redução significativa apenas nas parcelas de dispêndio relativas à higiene.

Comparando esses resultados com aqueles apresentados na Tabela 2, verifica-se que os resultados, em termos absolutos e relativos, foram distintos nas categorias educação, higiene e recreação, nos domicílios femininos. Por outro lado, nos domicílios mistos, as distinções se deram nas parcelas relacionadas a fumo, serviços pessoais e transporte.

Com relação à alimentação, houve uma redução da parcela relativa a esta categoria, nos domicílios mistos, de cerca de 6,5 p.p., enquanto, nos domicílios femininos, a alteração não foi significativa, o que pode ser justificado pelo fato de que, antes da política, o consumo alimentar já se encontrava no patamar desejado. Por outro lado, nos domicílios mistos, as mulheres podem ter tentado manter os gastos com alimentação, mas não obtiveram êxito.

De qualquer forma, esse resultado contradiz os obtidos na literatura, na medida em que ela aponta aumento dos gastos com alimentação, tanto em termos relativos como absolutos. Cruz (2013), por exemplo, verificou que as beneficiárias do PBF relatam mudanças, sobretudo, na alimentação, após começarem a receber o PBF.

Djebbari (2005) também concluiu que, quando uma mulher do domicílio passa a auferir ou ter sua renda aumentada, o consumo de alimentos, medido em termos do consumo de calorias mensal, tende a aumentar substancialmente. Por outro lado, quando isso acontece com um homem, o consumo alimentar tende a cair consideravelmente.

O aumento do poder da mulher pode ser constatado, entretanto, no aumento da parcela dos gastos com despesas diversas (0,57 p.p.), educação (0,27 p.p.), saúde (1,21 p.p.) e vestuário (0,50 p.p.). A variação na parcela de dispêndio com saúde pode ter se dado em função da condicionalidade de saúde, que incentiva os cuidados e, de certa forma, estimula os gastos. Além disso, historicamente, as mulheres são mais preocupadas com sua saúde e com a saúde dos membros de sua família do que os homens. O aumento da parcela de dispêndio destinada à saúde pode relacionar-se, ainda, com a preferência das mulheres por alocar mais recursos do que os homens em investimentos com retornos no futuro (Rubalcava et al. 2009), sobretudo, se esses recursos estiverem sendo empregados na prevenção de doenças.

Esperava-se também que não houvesse nenhuma alteração significativa nos domicílios femininos, pois, neles, a alocação já era feita pela mulher antes do redesenho do programa. Assim, com o incremento de renda, haveria um aumento dos valores absolutos destinados a cada categoria, porém, em termos relativos, não haveria mudanças. Nesse sentido, Rubalcava et. al (2009) afirmam que, quando as mulheres decidem o destino da renda, elas, geralmente, a alocam para a melhoria nutricional da família. No entanto, eles dizem, ainda, que o gasto com bens para crianças, especialmente com roupas, também tende a aumentar. Contudo, os 
Mirian Aparecida Rocha, Leonardo Bornacki de Mattos, Alexandre Bragança Coelho

resultados encontrados não apontam elevação da parcela de dispêndio referente à alimentação, embora o aumento dos gastos com vestuário tenha se verificado.

Essa falta de padrão dos gastos com as parcelas de dispêndio pode ser explicada segundo a visão de Phipps e Burton (1998), os quais examinaram os gastos das famílias canadenses no início da década de 1990 e concluíram que maridos e mulheres agregam recursos (hipótese do modelo unitário) para algumas categorias de despesa, mas não para outras. No primeiro caso, encontram-se as despesas ligadas à habitação, lazer, fumo, doações e álcool. No caso das despesas para as quais a hipótese de agregação de recursos foi rejeitada estão alimentação, dentro e fora de casa, vestuário, cuidados com crianças e transporte. Os autores concluem, então, que os gastos com as esferas tradicionalmente imputadas às mulheres aumentam mais rapidamente com a renda das esposas do que com a dos maridos; e o mesmo ocorre no caso dos homens. Assim, a renda das mulheres tem mais probabilidade de ser usada com alimentação, roupas de criança e cuidados com crianças, enquanto a renda dos homens está relacionada aos gastos com transporte e roupas de homem. Dessa forma, conclui-se que, para a maior parte das despesas familiares, o modelo das esferas separadas (modelo coletivo) é o mais adequado.

Os resultados encontrados não são na sua totalidade semelhantes aos de Phipps e Burton (1998), porém, a ideia de que os casais agregam determinados recursos e outros não pode explicar a significância das variações de apenas algumas parcelas de dispêndio.

Dado que a variação do consumo poderia ser atribuída ao maior poder da mulher exclusivamente nas categorias em que o aumento do consumo fosse significativo apenas para domicílios mistos (e não para os femininos), pode-se afirmar que o aumento do poder de barganha da mulher, conferido pelo PBF, foi significativo para aumentar as parcelas de dispêndio relativas à educação, saúde, serviços pessoais, vestuário e despesas diversas.

\section{Conclusão}

A fim de verificar como o Programa Bolsa Família alterou os padrões de consumo das famílias brasileiras, analisou-se o impacto do PBF sobre a alocação da renda em diferentes categorias de consumo nos domicílios com renda per capita até $\mathrm{R} \$ 140,00$ e entre $\mathrm{R} \$ 140,00$ e $\mathrm{R} \$ 400,00$. E, com o intuito de averiguar se o PBF, ao destinar renda preferencialmente às mulheres, aumentou o seu poder na alocação da renda dentro do domicílio, estudou-se o impacto do PBF sobre domicílios mistos e femininos.

Para que se pudesse parear domicílios beneficiários e não beneficiários, foi empregado o Propensity Score Matching, que permitiu concluir que apenas as variáveis número de moradores, presença de crianças e/ou adolescentes, e as variáveis relativas à localização do domicílio, Região Nordeste e Sul, aumentam a probabilidade do domicílio se tornar beneficiário do PBF. De posse dos propensity scores, foi possível realizar o matching e avaliar o impacto do PBF sobre a alocação da renda em diferentes categorias de consumo nos domicílios beneficiários. 
Influência do Programa Bolsa Família na alocação de recursos: uma análise considerando a presença de mulheres...

Com relação à influência das mulheres na alocação de recursos nos domicílios beneficiários do PBF, conclui-se que, para as categorias em que o PBF não foi significativo para alterar os recursos destinados a elas pode-se afirmar que vale o modelo de preferências comuns (modelo unitário), de maneira que, o efeito de uma renda adicional para as mulheres é o mesmo que o efeito de uma renda adicional para os homens. Os bens dessas categorias podem ser considerados "públicos" dentro do domicílio. Dessa forma, a única categoria em que não vale o modelo coletivo é fumo, o que significa que destinar renda às mulheres não afeta o consumo de itens relacionados na categoria fumo. Porém, em termos relativos, a única categoria em que vale o modelo unitário é vestuário.

Verificou-se, portanto, que o modelo coletivo se aplica a todas as demais categorias. Pode-se concluir que transferir renda para a mulher influencia na forma como o domicílio aloca a renda. Talvez essa influência se limite à renda do PBF e não ao rendimento total do domicílio. Porém, o PBF garante à mulher acesso à renda, ter dinheiro próprio e a certeza de que poderá escolher como gastá-lo. Com isso, pode-se iniciar um processo de desestabilização das hierarquias de poder internalizadas nas famílias. Essas mulheres podem começar a alcançar potencialidades de transformar as negociações cotidianas, mesmo que timidamente, como por exemplo, não ter que pedir mais dinheiro para o marido para realizar os gastos com a casa e com os filhos.

Os resultados, em geral, são menores nos domicílios mistos, em comparação aos femininos, o que indica que, nos domicílios em que as mulheres têm total autonomia para alocar a renda do PBF, o impacto do acréscimo da renda foi maior. Contudo, não se pode mudar uma estrutura estabelecida há séculos nos domicílios, em que as decisões de consumo intradomiciliares eram tomadas pelos homens, em poucos anos. É preciso que essa autonomia seja fortalecida constantemente e que outras políticas reforcem as transferências de renda. Por outro lado, não se pode ignorar as mudanças ocorridas, uma vez que elas retratam a existência de diferenças nas preferências entre homens e mulheres.

Ressalta-se que os dados utilizados nesta pesquisa apresentam algumas limitações, tais como os domicílios estudados no ano de 2008 não se referirem aos mesmos domicílios analisados em 2002, visto que a POF realiza nova amostragem a cada edição. Não é possível verificar como era o padrão de consumo do domicílio que recebia o PBF em 2002, sendo necessário examinar o comportamento dos domicílios beneficiários de outros programas de transferência renda. Assim, os resultados obtidos referem-se ao impacto do PBF em relação aos programas existentes em 2002, Bolsa Escola, Auxílio Gás e PETI.

Tendo em vista que os recursos do Programa Bolsa Família são destinados, sobretudo para alimentação e habitação das famílias beneficiárias, estas são as principais áreas para as quais o governo deve direcionar esforços, em termos de políticas públicas. Espera-se que deva haver um fortalecimento dos programas de segurança alimentar que possibilitem a oferta de produtos alimentares adequados e pouco consumidos, como legumes, verduras, frutas e carnes. 
Mirian Aparecida Rocha, Leonardo Bornacki de Mattos, Alexandre Bragança Coelho

Também é importante fortalecer as condicionalidades, ampliando as palestras e cursos oferecidos pelos Centros de Referência da Assistência Social (CRAS) e pelos Centros de Referência Especializados da Assistência Social (CREAS), que, pelo conteúdo informativo, ajudam as famílias a priorizar itens mais saudáveis para alimentação de crianças e adultos, fornecem informações importantes de higiene e cuidados simples de saúde, que podem melhorar sobremaneira a qualidade de vida nesses domicílios e a destinação dos recursos recebidos do PBF.

\section{Bibliografia}

ALTONJI, J. et al. Is the extended family altruistically linked? Direct tests using micro data. Cambridge, Mass: National Bureau of Economic Research, 1993. (Working Paper, n. 3046).

ANGELUCCI, M.; ATTANASIO, O. (). The demand for food of poor urban Mexican households: understanding policy impacts using structural models. American Economic Journal: Economic Policy, v. 5, n. 1, p. 146-205, 2013.

ANGRIST, J.; PISCHKE, J. S. Mostly harmless econometrics: An empiricist's companion. Princeton, NJ: Princeton University Press, 2008.

ATTANASIO, O. et al. Food and cash transfers: evidence from Colombia. The Economic Journal, v. 122, n. 559, p. 92-124, 2012.

BAPTISTELLA, J. C. Avaliação de programas sociais: uma análise do Bolsa Família sobre o consumo de alimentos. Dissertação (Mestrado em Economia Aplicada)-Universidade Federal de São Carlos, 2012.

BECKER, G. A theory of allocation of time. Economic Journal, v. 75, n. 299, p. 493-517, 1965.

BECKER, G. A treatise on the family. Harvard University Press, 1991.

BECKER, S. O.; ICHINO, A. Estimation of average treatment effects based on propensity scores. The Stata Journal, v. 2, n. 4, p. 358-377, 2002.

BROWNING, M. et al. Income and outcomes: a structural model of intrahousehold allocation. Journal of Political Economy, v. 102, n. 6, p. 1067-1096, 1994.

BROWNING, M. et al. Collective and unitary models: a clarification. Review of Economics of the Household, v. 4, n. 1, p. 5-14, 2006.

CHIAPPORI, P. A. Rational household labor supply. Econometrica: Journal of the Econometric Society, v. 56, n. 1, p. 63-90, 1988.

CRUZ, L. R. As portas do Programa Bolsa Família: vozes das mulheres beneficiárias do município de Santo Antonio do Pinhal/SP. In: ENCONTRO NACIONAL DE ESTUDOS POPULACIONAIS, 19. Anais... São Paulo: ABEP, 2013. 
Influência do Programa Bolsa Família na alocação de recursos: uma análise considerando a presença de mulheres...

DJEBBARI, H. The impact on nutrition of the intrahousehold distribution of power. Institute of Labor Economics, IZA, 2005. (Discussion Papers, n. 1701).

FAHEL, M. et al. O impacto do Bolsa Família no desempenho escolar em Belo Horizonte: spillover effect da condicionalidade-educação1. In: CONGRESO LATINOAMERICANO DE SOCIOLOGIA, 29, 2013.

FAVERO, C.; SANTOS, S. O Programa Bolsa Família e as relações de gênero e geração na agricultura familiar do semiárido do Nordeste. In: B. M. Fome. Avaliação de políticas públicas: reflexões acadêmicas sobre o desenvolvimento social e o combate à fome Brasília, DF: Secretaria de Avaliação e Gestão da Informação, 2014. p. 122-147.

FERRARIO, M. N. Análise do impacto dos programas de transferência de renda sobre as despesas familiares com o consumo. Tese (Doutorado em Economia)-Universidade de São Paulo (ESALQ), 2013.

GRONAU, R. Leisure, home production, and work - the theory of allocation of time revisited. Journal of Political Economy, v. 8, n. 6, p. 1099-1123, 1977,

INSTITUTO BRASILEIRO DE GEOGRAFIA E ESTATÍSTICA - IBGE. Pesquisa de Orçamentos Familiares 2008-2009: despesas, rendimentos e condições de vida. Rio de Janeiro, 2010.

KHANDKER, S. R. et al. Handbook on impact evaluation: quantitative methods and practices. World Bank Publications, 2010.

MALUCCIO, J.; FLORES, R. Impact evaluation of a conditional cash transfer program: the Nicaraguan Red de Protección Social, 2004. (FNDC Discussion Paper).

MENEZES-FILHO, N. Avaliação econômica de projetos sociais. São Paulo: Dinâmica Gráfica e Editora, 2012.

MINISTÉRIO DO DESENVOLVIMENTO SOCIAL E COMBATE À FOME - MDS. Ministério do Desenvolvimento Social e Combate à Fome. 2014. Acesso em: 20 out. 2014. Disponível em: http://www.mds.gov.br/.

PHIPPS, S. A.; BURTON, P. What's mine is yours? The influence of male and female incomes on patterns of household expenditures. Economica, v. 65, n. 160, p. 599-613, 1998.

PINHEIRO, L.; FONTOURA, N. Perfil das despesas e dos rendimentos das famílias brasileiras sob a perspectiva de gênero. In: GASTO e consumo das famílias brasileiras contemporâneas, v. 2, 2007.

ROSENBAUM, P. R.; RUBIN, D. B. Constructing a control group using multivariate matched sampling methods that incorporate the propensity score. The American Statistician, v. 39, n. 1, p. 33-38, 1985. 
Mirian Aparecida Rocha, Leonardo Bornacki de Mattos, Alexandre Bragança Coelho

RUBALCAVA, L. et al. Investments, time preferences, and public transfers paid to women. Economic Development and Cultural Change, v. 57, n. 30, p. 507-538, 2009.

SANTOS, A. H. da S.. Redução da desigualdade de renda no Brasil: determinantes e consequências. Tese (Doutorado)-Universidade de Brasília, 2012.

SCHADY, N.; ROSERO, J. Are cash transfers made to women spent like other sources of income? Economic Letters, v. 101, n. 3, p. 246-248, 2008.

SILVEIRA NETO, R. Impacto do Programa Bolsa Família sobre a frequência à escola: estimativas a partir de informações da Pesquisa Nacional de Amostra por Domicílio (PNAD). In: BOLSA Família 2003-2010: avanços e desafios. Ipea, 2010.

SUÁREZ, M.; LINBARDONI, M. O impacto do Programa Bolsa Família: mudanças e continuidades na condição social das mulheres. In: AVALIAÇÃO de políticas e programas do MDS: resultados, 2007. v. 2, p. 119-162.

THOMAS, D. The distribution of income and expenditure within the household. Annales d'Economie et de Statistique, n. 29, p. 109-135, 1993.

THOMAS, D.; CHEN, C. L. Income shares and shares of income: empirical tests of models of household resource allocations. RAND, 1994.

UDRY, C. Credit markets in Northern Nigeria: credit as insurance in a rural economy. The World Bank Economic Review, v. 4, n. 3, p. 251-269, 1990. 
Influência do Programa Bolsa Família na alocação de recursos: uma análise considerando a presença de mulheres...

\section{Anexo}

Tabela A1

Probabilidade de participação nos programas de transferência de renda dos domicílios mistos com renda per capita de até $\mathrm{R} \$ 140,00$ para os anos de 2002 e de 2008, Brasil

\begin{tabular}{|c|c|c|c|c|c|c|}
\hline \multirow{2}{*}{ Variável } & \multicolumn{3}{|c|}{$2002-2003$} & \multicolumn{3}{|c|}{ 2008-2009 } \\
\hline & Coeficiente & Erros-padrão & P-valor & Coeficiente & Erros-padrão & P-valor \\
\hline Chefe mulher & $-0,044^{\mathrm{NS}}$ & 0,074 & 0,589 & $-0,166^{* *}$ & 0,66 & 0,012 \\
\hline $\begin{array}{l}\text { Presença de } \\
\text { crianças/adolescentes }\end{array}$ & $1,01 * * *$ & 0,099 & 0 & $0,713 * * *$ & 0,075 & 0 \\
\hline Presença de adultos & $-0,24^{\mathrm{NS}}$ & 0,26 & 0,354 & $0,049 \mathrm{NS}$ & 0,304 & 0,871 \\
\hline Presença de idosos & $-0,21 * *$ & 0,109 & 0,049 & $-0,51 * * *$ & 0,074 & 0 \\
\hline Área urbana & $-0,25 * * *$ & 0,038 & 0 & $-0,229 * * *$ & 0,045 & 0 \\
\hline Presença de aposentados & $0,001^{\mathrm{NS}}$ & 0,078 & 0,983 & $-0,54 \mathrm{NS}$ & 0,058 & 0,354 \\
\hline Cor do chefe (branco) & $-0,002^{\mathrm{NS}}$ & 0,048 & 0,959 & $0,015 \mathrm{NS}$ & 0,03 & 0,606 \\
\hline Região Norte & $-0,14^{*}$ & 0,072 & 0,052 & $0,376^{* * *}$ & 0,08 & 0 \\
\hline Região Nordeste & $0,50 * * *$ & 0,058 & 0 & $0,83 * * *$ & 0,071 & 0 \\
\hline Região Sul & $0,27 * * *$ & 0,085 & 0,001 & $-0,077 \mathrm{NS}$ & 0,101 & 0,445 \\
\hline Região Sudeste & $0,12^{\mathrm{NS}}$ & 0,087 & 0,162 & $0,145 \mathrm{NS}$ & 0,094 & 0,124 \\
\hline Anos de estudo do chefe & $-0,02 * *$ & 0,01 & 0,033 & $-0,043 * * *$ & 0,006 & 0 \\
\hline $\begin{array}{l}\text { Anos de estudos da } \\
\text { mulher }\end{array}$ & $-0,008^{N S}$ & 0,008 & 0,301 & $-0,326 * * *$ & 0,007 & 0,002 \\
\hline Número de moradores & $0,10^{* * *}$ & 0,011 & 0 & $0,099 * * *$ & 0,013 & 0 \\
\hline Renda per capita $(\ln )$ & $-0,002 * * *$ & 0,0005 & 0 & $-0,002 * * *$ & 0 & 0 \\
\hline Constante & $-1,72 * * *$ & 0,28 & 0 & $-0,906 * * *$ & 0,312 & 0,004 \\
\hline N. de observações & 10937 & & & 8045 & & \\
\hline Pseudo $\mathrm{R}^{2}$ & 0,1033 & & & 0,1592 & & \\
\hline
\end{tabular}

$* * *$ significativo a $1 \%$. **significativo a $5 \%$. *significativo a $10 \%$. NS: Não Significativo

Notas:

(1) Valores em R \& e a preços constantes de 15/01/2009, deflacionados pelo IPCA-15.

(2) Os valores referentes à renda dos domicílios beneficiários não incluem as transferências de renda dos programas Bolsa Família, Bolsa Escola, Auxílio Gás e PETI.

Fonte: Dados da pesquisa. 
Tabela A2

Média das variáveis de controle antes e depois do matching para os domicílios mistos com renda per capita de até $\mathrm{R} \$ 140,00$

\begin{tabular}{|c|c|c|c|c|c|c|c|}
\hline Variável & Matching & Tratamento & Controle & $\%$ viés & $\begin{array}{c}\% \text { de } \\
\text { redução } \\
\text { do viés }\end{array}$ & $\mathrm{T}$ & $\mathrm{p}>\mathrm{t}$ \\
\hline \multirow{2}{*}{$\begin{array}{l}\text { Presença de crianças } \\
\text { / adolescentes }\end{array}$} & Antes & 0.967 & 0.870 & 36,30 & \multirow{2}{*}{97,7} & 22,87 & 0.00 \\
\hline & Depois & 0.967 & 0.970 & $-0,80$ & & $-0,77$ & 0.44 \\
\hline \multirow{2}{*}{ Presença de adultos } & Antes & 0.996 & 0.997 & 9,50 & \multirow{2}{*}{81} & 6,04 & 0.00 \\
\hline & Depois & 0.996 & 0.994 & 1,80 & & 1,44 & 0.15 \\
\hline \multirow{2}{*}{ Presença de idosos } & Antes & 0.101 & 0.163 & $-18,40$ & \multirow{2}{*}{68} & $-12,05$ & 0.00 \\
\hline & Depois & 0.101 & 0,121 & $-5,90$ & & $-3,82$ & 0,00 \\
\hline \multirow{2}{*}{ Área urbana } & Antes & 0.565 & 0.656 & $-18,70$ & \multirow{2}{*}{93,2} & $-12,59$ & 0.00 \\
\hline & Depois & 0.566 & 0.559 & 1,30 & & 0,75 & 0.45 \\
\hline \multirow{2}{*}{$\begin{array}{l}\text { Anos de estudo do } \\
\text { chefe }\end{array}$} & Antes & 2,876 & 3,580 & $-22,50$ & \multirow{2}{*}{87,1} & $-14,79$ & 0.00 \\
\hline & Depois & 2,877 & 2,780 & 2,90 & & 1,86 & 0.06 \\
\hline \multirow{2}{*}{$\begin{array}{l}\text { Anos de estudo da } \\
\text { mulher }\end{array}$} & Antes & 2.934 & 3.243 & $-9,5$ & \multirow{2}{*}{48,5} & $-6,29$ & 0.00 \\
\hline & Depois & 2.935 & 2.777 & 4.9 & & 3,13 & 0.002 \\
\hline \multirow{2}{*}{$\begin{array}{l}\text { Número de } \\
\text { moradores }\end{array}$} & Antes & 5.487 & 4.726 & 3,86 & \multirow{2}{*}{92,6} & 26,01 & 0.00 \\
\hline & Depois & 5.492 & 5.549 & $-2,9$ & & $-1,54$ & 0,124 \\
\hline \multirow{2}{*}{$\begin{array}{l}\text { Presença de } \\
\text { aposentados }\end{array}$} & Antes & 0.163 & 0.192 & $-7,6$ & \multirow{2}{*}{36,6} & $-5,05$ & 0.00 \\
\hline & Depois & 0.163 & 0.181 & $-4,8$ & & $-2,94$ & 0,003 \\
\hline \multirow{2}{*}{$\begin{array}{l}\text { Cor do chefe } \\
\text { (branco) }\end{array}$} & Antes & 0.244 & 0.296 & $-9,3$ & \multirow{2}{*}{87,4} & $-6,28$ & 0.00 \\
\hline & Depois & 0.244 & 0.237 & 1,2 & & 0,72 & 0,472 \\
\hline \multirow{2}{*}{ Região Norte } & Antes & 0.157 & 0.213 & $-13,9$ & \multirow{2}{*}{97,2} & $-9,18$ & 0.00 \\
\hline & Depois & 0.157 & 0.159 & $-0,4$ & & $-0,25$ & 0,803 \\
\hline \multirow{2}{*}{ Região Nordeste } & Antes & 0.672 & 0.474 & 40,9 & \multirow{2}{*}{95.4} & 27,22 & 0.00 \\
\hline & Depois & 0.672 & 0.681 & $-1,9$ & & $-1,17$ & 0,242 \\
\hline \multirow{2}{*}{ Região Sul } & Antes & 0.032 & 0.062 & $-14,4$ & \multirow{2}{*}{96,4} & $-9,35$ & 0.00 \\
\hline & Depois & 0.032 & 0.031 & 0,5 & & 0,38 & 0,705 \\
\hline \multirow{2}{*}{ Região Sudeste } & Antes & 0.079 & 0.115 & $-12,1$ & \multirow{2}{*}{71,6} & $-7,93$ & 0.00 \\
\hline & Depois & 0.079 & 0.069 & 3,4 & & 2,33 & 0.02 \\
\hline \multirow{2}{*}{ In renda per capita } & Antes & 3,793 & 4,179 & $-26,3$ & \multirow{2}{*}{49,2} & $-19,25$ & 0.00 \\
\hline & Depois & 3,794 & 3,989 & $-13,3$ & & $-7,88$ & 0.00 \\
\hline
\end{tabular}

Notas: (1) Valores em R $\$$ e a preços constantes de 15/01/2009, deflacionados pelo IPCA-15.

(2) Os valores referentes à renda dos domicílios beneficiários não incluem as transferências de renda dos programas Bolsa Família, Bolsa Escola, Auxílio Gás e PETI.

Fonte: Dados da pesquisa. 
Influência do Programa Bolsa Família na alocação de recursos: uma análise considerando a presença de mulheres...

Tabela A3

Impacto do PBF sobre os dispêndios nas categorias de consumo em domicílios mistos e femininos, considerando adultos aqueles com idade superior a 15 anos, no período 2002-2008

\begin{tabular}{|c|c|c|c|c|}
\hline \multirow{2}{*}{ Categorias } & \multicolumn{2}{|c|}{ Domicílios mistos } & \multicolumn{2}{|c|}{ Domicílios com apenas mulheres } \\
\hline & NNM & $\mathrm{KM}$ & NNM & $\mathrm{KM}$ \\
\hline \multirow{2}{*}{ Despesas de consumo } & $30,56 * * *$ & $35,14 * * *$ & $72,88 * * *$ & $48,05^{* * *}$ \\
\hline & $(3,29)$ & $(2,01)$ & $(14,21)$ & $(8,90)$ \\
\hline \multirow{2}{*}{ Alimentação } & $6,25 * * *$ & $6,91 * * *$ & $12,65^{* *}$ & $9,89 * * *$ \\
\hline & $(1,57)$ & $(1,07)$ & $(5,54)$ & $(3,66)$ \\
\hline \multirow{2}{*}{ Despesas diversas } & $1,30 * * *$ & $1,20 * * *$ & $2,43 * *$ & $1,01 *$ \\
\hline & $(0,29)$ & $(0,14)$ & $(1,02)$ & $(0,55)$ \\
\hline \multirow{2}{*}{ Educação } & $0,02^{\mathrm{NS}}$ & $0,46 * * *$ & $1,75^{*}$ & $1,02 * * *$ \\
\hline & $(0,21)$ & $(0,09)$ & $(0,90)$ & $(0,24)$ \\
\hline \multirow{2}{*}{ Fumo } & $0,23^{\mathrm{NS}}$ & $0,34 * * *$ & $0,35^{\mathrm{NS}}$ & $0,41 * *$ \\
\hline & $(0,14)$ & $(0,10)$ & $(0,43)$ & $(0,19)$ \\
\hline \multirow{2}{*}{ Habitação } & $11,94 * * *$ & $12,02 * * *$ & $28,25 * * *$ & $21,63^{* * *}$ \\
\hline & $(1,03)$ & $(0,63)$ & $(7,26)$ & $(5,85)$ \\
\hline \multirow{2}{*}{ Higiene } & $0,87 * * *$ & $1,15 * * *$ & $4,14 * * *$ & $0,99^{\mathrm{NS}}$ \\
\hline & $(0,24)$ & $(0,15)$ & $(1,18)$ & $(0,72)$ \\
\hline \multirow{2}{*}{ Recreação } & $0,84 * * *$ & $0,78 * * *$ & $1,17 * *$ & $0,88 * *$ \\
\hline & $(0,13)$ & $(0,07)$ & $(0,46)$ & $(0,40)$ \\
\hline \multirow{2}{*}{ Saúde } & $3,07 * * *$ & $3,31 * * *$ & $6,29 * * *$ & $4,28 * * *$ \\
\hline & $(0,44)$ & $(0,33)$ & $(1,61)$ & $(0,88)$ \\
\hline \multirow{2}{*}{ Serviços pessoais } & $0,35^{* * *}$ & $0,47 * * *$ & $1,67 * * *$ & $1,10^{* * *}$ \\
\hline & $(0,08)$ & $(0,05)$ & $(0,32)$ & $(0,20)$ \\
\hline \multirow{2}{*}{ Transporte } & $2,95 * *$ & $5,70 * * *$ & $5,39^{\mathrm{NS}}$ & $2,23 *$ \\
\hline & $(1,36)$ & $(0,80)$ & $(4,50)$ & $(1,23)$ \\
\hline \multirow{2}{*}{ Vestuário } & $2,75 * * *$ & $2,80 * * *$ & $8,79 * * *$ & $4,61 * * *$ \\
\hline & $(0,39)$ & $(0,23)$ & $(1,49)$ & $(0,78)$ \\
\hline N. de observações & 7599 & 7599 & 984 & 984 \\
\hline
\end{tabular}

Fonte: Resultados da pesquisa.

$* * *$ significativo a $1 \%$. **significativo a $5 \%$. *significativo a $10 \%$. NS: Não Significativo.

Os valores entre parênteses se referem aos erros-padrão.

Notas: ${ }^{(1)}$ Valores em R\$ e a preços constantes de 15/01/2009, deflacionados pelo IPCA-15.

(2) Os valores referentes à renda dos domicílios beneficiários não incluem as transferências de renda dos programas Bolsa Família, Bolsa Escola, Auxílio Gás e PETI. 
Tabela A4

Impacto do PBF sobre as parcelas de dispêndio dos domicílios mistos, considerando adultos aqueles com idade superior a 15 anos

\begin{tabular}{|c|c|c|c|c|}
\hline \multirow[b]{2}{*}{ Parcelas } & \multicolumn{2}{|c|}{ Domicílios mistos } & \multicolumn{2}{|c|}{ Domicílios com apenas mulheres } \\
\hline & NNM & KM & NNM & KM \\
\hline \multirow{2}{*}{ Alimentação } & $-0,0578 * * *$ & $-0,0625 * * *$ & $-0,0025^{\mathrm{NS}}$ & $-0,0069^{\mathrm{NS}}$ \\
\hline & $(0,0075)$ & $(0,0050)$ & $(0,0227)$ & $(0,0155)$ \\
\hline \multirow{2}{*}{ Despesas diversas } & $0,0053 * * *$ & $0,0022 * *$ & $0,0212 * * *$ & $0,0017^{\mathrm{NS}}$ \\
\hline & $(0,0015)$ & $(0,0010)$ & $(0,0060)$ & $(0,0037)$ \\
\hline \multirow{2}{*}{ Educação } & $0,0015^{\mathrm{NS}}$ & $0,0018 * *$ & $-0,0036^{\mathrm{NS}}$ & $-0,0026^{\mathrm{NS}}$ \\
\hline & $(0,0010)$ & $(0,0007)$ & $(0,0033)$ & $(0,0025)$ \\
\hline \multirow{2}{*}{ Fumo } & $-0,0039 * *$ & $-0,0043 * * *$ & $0,0055^{*}$ & $0,0010^{\mathrm{NS}}$ \\
\hline & $(0,0017)$ & $(0,0010)$ & $(0,0031)$ & $(0,0018)$ \\
\hline \multirow{2}{*}{ Habitação } & $0,0337 * * *$ & $0,0478 * * *$ & $0,0263^{\mathrm{NS}}$ & $0,0288^{*}$ \\
\hline & $(0,0060)$ & $(0,0039)$ & $(0,0209)$ & $(0,0147)$ \\
\hline \multirow{2}{*}{ Higiene } & $-0,0027^{\mathrm{NS}}$ & $-0,0015^{\mathrm{NS}}$ & $-0,0100^{\mathrm{NS}}$ & $-0,0143 * * *$ \\
\hline & $(0,0017)$ & $(0,0011)$ & $(0,0061)$ & $(0,0044)$ \\
\hline \multirow{2}{*}{ Recreação } & $0,0036 * * *$ & $0,0035 * * *$ & $-0,0009^{\mathrm{NS}}$ & $0,0017^{\mathrm{NS}}$ \\
\hline & $(0,0009)$ & $(0,0006)$ & $(0,0031)$ & $(0,0018)$ \\
\hline \multirow{2}{*}{ Saúde } & $0,0128 * * *$ & $0,0117 * * *$ & $-0,0022^{\mathrm{NS}}$ & $0,0103 *$ \\
\hline & $(0,0031)$ & $(0,0022)$ & $(0,0092)$ & $(0,0058)$ \\
\hline \multirow{2}{*}{ Serviços pessoais } & $0,0005^{\mathrm{NS}}$ & $0,0014 * * *$ & $0,0012^{\mathrm{NS}}$ & $0,0035 * * *$ \\
\hline & $(0,0008)$ & $(0,0004)$ & $(0,0023)$ & $(0,0011)$ \\
\hline \multirow{2}{*}{ Transporte } & $0,0022^{\mathrm{NS}}$ & $-0,0044^{\mathrm{NS}}$ & $-0,0381 * * *$ & $-0,0255 * * *$ \\
\hline & $(0,0050)$ & $(0,0034)$ & $(0,0126)$ & $(0,0081)$ \\
\hline \multirow{2}{*}{ Vestuário } & $0,0047^{\mathrm{NS}}$ & $0,0042 * *$ & $0,0031^{\mathrm{NS}}$ & $0,0023^{\mathrm{NS}}$ \\
\hline & $(0,0029)$ & $(0,0019)$ & $(0,0089)$ & $(0,0057)$ \\
\hline N. de observações & 7545 & 7545 & 976 & 976 \\
\hline
\end{tabular}

$* * *$ significativo a $1 \%$. **significativo a $5 \%$. *significativo a $10 \%$. NS: Não Significativo.

Os valores entre parênteses se referem aos erros-padrão.

Notas: (1) Valores em R\$ e a preços constantes de 15/01/2009, deflacionados pelo IPCA-15.

(2) Os valores referentes à renda dos domicílios beneficiários não incluem as transferências de renda dos programas Bolsa Família, Bolsa Escola, Auxílio Gás e PETI.

Fonte: Resultados da pesquisa. 